\title{
A 25-year climatology of low-tropospheric temperature and humidity inversions for contrasting synoptic regimes at Neumayer Station, Antarctica
}

Tiago Silva ${ }^{1,2}$ and Elisabeth Schlosser ${ }^{1,3}$

${ }^{1}$ Department of Atmospheric and Cryospheric Sciences, University of Innsbruck, Innsbruck, Austria

${ }^{2}$ Department of Geography and Regional Science, University of Graz, Graz, Austria

${ }^{3}$ Austrian Polar Research Institute, Vienna, Austria

Correspondence: Tiago Silva (tiago.ferreira-da-silva@uni-graz.at)

\begin{abstract}
A 25-year set of daily radiosonde data was used to investigate temperature and humidity inversions at Neumayer Station, coastal Dronning Maud Land, Antarctica. For the first time, inversions were studied differentiating between different synoptic conditions and different height levels. It was shown that, generally, inversions occurred on the majority (78 \%) of the days, with simultaneous occurrence of humidity and temperature inversions being observed on approximately two thirds of all days. Multiple inversions are common in all seasons for both weather conditions, however, typically occur more frequently under cyclonic conditions. The seasonality of inversion occurrence and features, i.e. inversions strength, depth and vertical gradients, was analysed statistically. Different formation mechanisms depending on inversion levels and prevailing weather situations are related to typical annual courses of certain inversion features. Winter maxima were found for the features that are mostly connected to the temperature close to the surface, which is mainly a result of the negative energy balance, thus influencing surface-based inversions. At the second level, both temperature and humidity inversions are often caused by advection of comparably warm and moist air masses related to the passage of cyclones and their frontal systems. Thus maxima in several inversion features are found in spring and fall, when cyclonic activity is strongest. Monthly mean profiles of humidity and temperature inversions reveal that elevated inversions are often obscured in average profiles due to large variations in inversion height and depth.
\end{abstract}

\section{Introduction}

Temperature and humidity inversions are a common feature of the stable boundary layer (SBL) in polar regions (e.g. King and Turner 2007; Nygård et al. 2013; Phillpot and Zillman 1970; Vignon et al. 2019, Zhang et al. 2011). The lack of turbulent mixing and thus reduced vertical transport of heat and moisture leads to strong inversions close to the surface. They often occur within the first hundreds of meters above the ground in all seasons, but are most pronounced in winter (Zhang et al., 2011). Relatively little is known about elevated inversions with base heights between $50 \mathrm{~m}$ and $2500 \mathrm{~m}$ above the surface.

In particular, humidity inversions play an important role in the hydrological cycle of Antarctica, which is enhanced in cases of atmospheric rivers that lead to large amounts of precipitation, thus linking humidity inversions to the surface mass balance of 
https://doi.org/10.5194/wcd-2021-22

Preprint. Discussion started: 10 May 2021

(c) Author(s) 2021. CC BY 4.0 License.

(c) (i)

Weather and

Climate Dynamics

Discussions

Antarctica and consequently to sea level changes (Gorodetskaya et al., 2020). In spite of the importance of humidity inversions for both the local meteorological conditions and the mass balance of high-latitude ice sheets (King and Turner, 2007), they have received much less attention than temperature inversions and their formation mechanisms in the past. Understanding of dynamical processes in the entire troposphere is essential for weather and climate studies.

A special application, for which a thorough understanding of inversions is required, is the paleoclimatic interpretation of ice cores. The derivation of paleotemperatures from stable water isotopes is based on the relationship between stable isotope ratios of the ice and the condensation temperature, not the surface temperature. At most deep ice core drilling sites strong inversions prevail, which has to be taken into account for a correct interpretation of ice core data.

In the polar regions, strong and thick surface-based inversions are supported by the large solar zenith angle, the high surface albedo, and the prolonged absence of solar radiation during the polar night (Andreas et al., 2000). Even under clear-sky conditions, the presence of temperature (Bintanja et al., 2011) and humidity (Devasthale et al., 2011) inversions contributes to warming of layers underneath through increased downward long-wave radiation and attenuation of long-wave emission. Ohmura (2001) found that 70-90 \% of the downward long-wave radiation measured at the surface is emitted from the lowest $1000 \mathrm{~m}$ of the atmosphere. Humidity inversions have a significant impact on the radiative characteristics of the atmosphere (Devasthale et al., 2011). Elevated inversions are often associated with horizontal advection of relatively warm and moist air masses from lower latitudes by synoptic-scale processes (Brunke et al., 2015). The relationship between inversions at different levels and between temperature and humidity inversions is complex and, particularly in Antarctica, has not been thoroughly investigated so far.

Traditionally, radiosondes have been launched mainly for operational weather forecasting, nowadays they have become important for additional applications, including model verification, climate research, and the verification of satellite data (Durre et al., 2006).

Various studies employed radiosonde data and/or remote sensing techniques to study the lowest part of the troposphere in the Arctic (e.g. Devasthale et al. 2011; Kahl 1990; Liu et al. 2006; Vihma et al. 2011) and Antarctic (e.g. Andreas et al. 2000; Dufour et al. 2019; König-Langlo and Loose 2007; Nygård et al. 2013; Tomasi et al. 2011; Vignon et al. 2019), or in both hemispheres (e.g. Pavelsky et al. 2011; Zhang et al. 2011). Most of them had restricted temporal coverage and did not distinguish between different weather conditions. For Neumayer, only one previous study is available that investigates temperature inversions. However, Neumayer radiosonde data are included in two other studies of Antarctic inversions. KönigLanglo and Loose (2007) found that surface-based inversions are common at Neumayer with a maximum of occurrence in winter and a minimum in summer. $75 \%$ of all inversions exhibit a strength, i.e. temperature difference between inversion base and top, of more than $1 \mathrm{~K}$ and values up to $25 \mathrm{~K}$ can be reached. However, their study mainly considered surfacebased inversions under anti-cyclonic conditions. Nygård et al. (2013) used data from 11 coastal Antarctic stations, including Neumayer, to create a 10-year climatology of humidity inversions. They state that generally humidity inversions occur most frequently in winter and spring and roughly half of the inversions occur simultaneously with temperature inversions. In a recent study, Vignon et al. (2019) combined an 8-year data set from nine Antarctic coastal stations including Neumayer to analyse the vertical structure of the lowest $3 \mathrm{~km}$ of the tropophere. They found fundamentally different conditions at the various stations 
https://doi.org/10.5194/wcd-2021-22

Preprint. Discussion started: 10 May 2021

(c) Author(s) 2021. CC BY 4.0 License.

Weather and

Climate Dynamics

(c) (i)

depending on the topography, namely ice shelf stations, strongly katabatically influenced locations and stations in a complex orography. In particular, a katabatic regime has a strong influence on humidity due to sublimation processes. At Neumayer, this is of minor importance. They also assessed the ability of two reanalysis products, ERA-Interim and ERA-5, to represent inversions and generally the structure of the lower troposphere and found that even for state-of-the-art atmospheric models, this remains a challenge.

Most recently, Gorodetskaya et al. (2020) presented a study of atmospheric rivers for Neumayer and Syowa Stations, both coastal Antarctica. Atmospheric river events mean strongly enhanced poleward moisture transport leading to extraordinarily high precipitation amounts. Gorodetskaya et al. (2020) showed that a strong humidity and temperature inversion is found through the mid-troposphere for atmospheric rivers, linked to an intensified low-level jet (LLJ).

In extremely cold environments, radiosonde measurements remain a challenge and error possibilities are large. For instance, humidity sensors often experience a dry-bias caused by solar heating (e.g. Gettelman et al. 2006; Miloshevich et al. 2001; Rowe et al. 2008) or a moist-bias resulting from condensation and icing on the sensor when exposed to supercooled water (Nash, 2015). The delayed response of the sensors in an ascending radiosonde can also lead to errors, particularly close to saturation and where large vertical gradients in temperature and humidity occur. However, Hudson et al. (2004) showed that radiosondes can yield reliable results when sensors are properly calibrated to ambient conditions before launch.

At the German Antarctic wintering base, Neumayer, in coastal Dronning Maud Land, radiosonde measurements have been carried out daily since 1981. In this study, a 25-yr data set (1993 -2017) was used in combination with the corresponding meteorological surface data (SYNOP) to study temperature and humidity inversions and their interrelations. We present the first comprehensive, long-term analysis of temperature and humidity inversions at an Antarctic coastal station. Since formation mechanisms are different for surface-based and elevated inversions as well as for different weather conditions, for the first time, an inversion climatology was created dependent on weather conditions, inversion base height and season by statistically analysing inversion frequency, depth, strength and vertical gradients. Additionally, the relationship between inversion features as well as between temperature and humidity inversions and between inversions at different levels was investigated.

\section{Data and Methods}

\subsection{Study period and location}

To assess the quality of radiosonde products is generally a challenging task. Dufour et al. (2019) compared radiosonde data from various Antarctic stations to four reanalysis products, namely ERA-Interim, NCEP-CFSR, JRA 55 and MERRA 2. For Neumayer Station, the vertically integrated moisture transport anomalies agree well with the four reanalyses products from 1993 onwards. Since the timing of good agreement was different for other stations, we conclude that it is not due to an improvement in the reanalyses data, but hints at a higher quality of the radiosonde data. Thus the 25-year period 1993-2017 was chosen for the present study, which was initiated in 2018.

Neumayer Station was constructed in 1981 on the Ekström Ice Shelf in coastal Dronning Maud Land, East Antarctica. The first base was given up for technical reasons and substituted by Neumayer II $\left(70^{\circ} 39^{\prime} \mathrm{S}, 8^{\circ} 15^{\prime} \mathrm{W}\right)$ in 1992 ; and in February 
2009, Neumayer II was replaced by Neumayer III (7040’ S, $8^{\circ} 16^{\prime} \mathrm{W}$, hereafter called "Neumayer"), $5 \mathrm{~km}$ south of the former base (Wesche et al., 2016). For our study, only data from Neumayer II and III were used.

At Neumayer, the sun stays permanently above the horizon from 19 November to 24 January (polar day) and permanently below the horizon from 19 May to 27 July (polar night) (König-Langlo and Loose, 2007). Ekström Ice Shelf is one of the smaller ice shelves in Antarctica, stretching south for approximately $120 \mathrm{~km}$ and is bordered by ridges of ca. $500 \mathrm{~m}$ elevation to the east and west. The surrounding ocean is covered by sea ice for the largest part of the year, only between mid-January and mid-March the coast becomes ice-free.

\subsection{Synoptic weather observations}

Since March 1981, SYNOP observations have been carried out at Neumayer every three hours between 0 and 21 UTC. At night (3 and 6 UTC), the observations are performed only automatically, thus no visual observations (weather, clouds, visibility) are included. Measurements of surface pressure, temperature (at $2 \mathrm{~m}$ ), dew-point temperature (at $2 \mathrm{~m}$ ) and wind vector (at $10 \mathrm{~m}$ height) are provided.

These data are coded in FM12-SYNOP format and directly transferred to the Global Telecommunication Service (GTS) under the World Meteorological Organization (WMO) code-number 89002, where it contributes to global weather forecasting models (König-Langlo and Loose, 2007). The 25-year series of SYNOP data is available at the Baseline Surface Radiation Network (BSRN), which collects and archives high-quality ground-based radiation measurements (Driemel et al., 2018). The 12 UTC SYNOP data were used to classify inversions depending on the general weather condition (see Subsection 2.4).

\subsection{Upper air soundings}

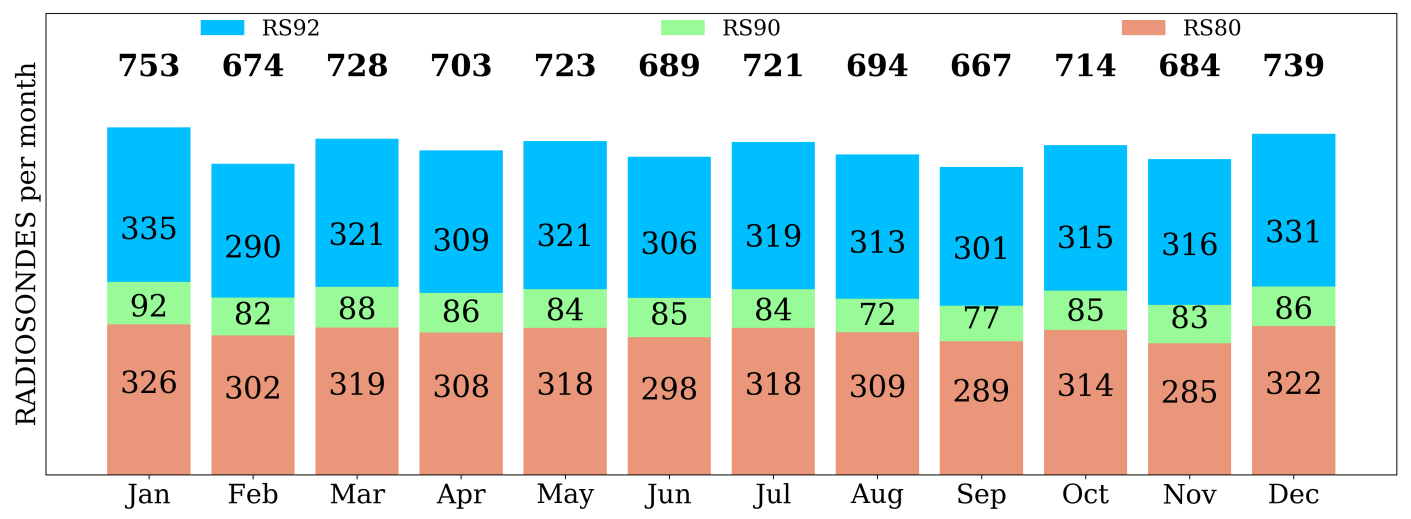

Figure 1. Total monthly radiosonde availability (bold numbers) from Baseline Surface Radiation Network under the stipulated criteria; the total monthly radiosonde availability depending on the radiosonde type used is indicated by the colored bar portions 
https://doi.org/10.5194/wcd-2021-22

Preprint. Discussion started: 10 May 2021

(c) Author(s) 2021. CC BY 4.0 License.

Weather and

Climate Dynamics

Discussions

L.

At Neumayer Station, radiosonde data are available since 1983. Usually one balloon ascent is performed per day measuring atmospheric profiles of air pressure, temperature, dew point temperature and wind vector at high resolution (König-Langlo and Loose, 2007). Generally, the balloon is launched in the morning, so that the data are available for the GTS at 12 UTC. Deviations from this time can occur due to problems with the start because of high wind speeds or a too early bursting of the balloon. In those cases sometimes a second or even third balloon launch was carried out at a later time.

Different from the general requirements of the WMO for radiosonde data ( 5 pressure levels between the surface and the 500-hPa level) (Nash, 2015), for the present study, we require more than 10 pressure levels with the surface level having a pressure higher than $925 \mathrm{hPa}$, since at Neumayer the surface pressure is below $1000 \mathrm{hPa}$ (WMO standard) most of the time. Following these criteria, a total of 8489 observations is available, which corresponds to $93 \%$ of the days in the study period.

Figure 1 presents the total monthly sum of observations at Neumayer used in this study. The background color of each bar portion symbolizes the type of radiosonde device used. During the 25-year period, 3 types of radiosonde were launched. Until late 2003, Vaisala RS80 (red) was used, followed by Vaisala RS90 (green) until late 2006; for the remainder of the study period Vaisala RS92 (blue) was utilized. There is only one gap in the data for the entire month of November 2003. The number of successful launches is only slightly lower in autumn and spring than in the other seasons, potentially as a consequence of severe weather conditions (blizzards). Thus it is assumed that each month and season is similarly represented in the data set.

It has to be kept in mind that these data come from different sensors throughout the years. Not only the hardware, but also the software has been gradually improved. Various error possibilities exist, starting with the storage of the sondes. In extremely cold and dry environments, such as Antarctica, radiosonde storage and launch at near ambient temperatures is known to minimize errors due to thermal shock (Hudson et al., 2004). The current and typical launch procedure includes a period of temperature adjustment before launch, which allows the radiosonde to balance with the surface temperature.

For the early Vaisala RS80, wind profiles were tracked by receiving OMEGA terrestrial navigational signals with an antenna (Maturilli and Kayser, 2017). Since the late nineties, wind speed and direction are monitored via balloon motion tracking.

Some radiosonde humidity sensors experience a dry-bias caused by solar heating and a moist-bias error (e.g. Miloshevich et al., 2006 and Rowe et al., 2008), which may result from condensation and icing on the sensor when exposed to super cooled liquid water. From Vaisala RS80 to RS92, radiosondes at low temperatures in general are unable to respond quickly to the given sudden temperature change and the rapid decrease of water vapour near the surface leading to a potential time-lag at the first measured pressure levels (e.g. Miloshevich et al., 2001; Miloshevich et al., 2004; Tomasi et al., 2011; Wang et al., 2002,). For RS80, Miloshevich et al. (2001) estimated that maximum time-lag errors on relative humidity (RH) vary with temperature from about $\pm 5 \% \mathrm{RH}$ at $-20^{\circ} \mathrm{C}$ to $\pm 15 \% \mathrm{RH}$ at $-40{ }^{\circ} \mathrm{C}$. Such issues allowed the RS80-humidity sensor to form an ice coating on the sensor in liquid-water or ice-saturated conditions, which sometimes caused the measurement to remain near ice-saturation over large parts of the troposphere, not resembling the conditions of the ambient air (Maturilli and Kayser, 2017). Hudson et al. (2004) showed, however, that Vaisala RS80 radiosondes can measure temperature, pressure, and humidity accurately in Antarctica when sensors are properly calibrated to ambient conditions before launch.

In comparison to RS80, RS90 response is known to be much faster with an estimated time-lag of $2 \mathrm{~s}$ at $-20^{\circ} \mathrm{C}(\mathrm{Miloshevich}$ et al., 2004). For Vaisala RS90, as the humidity sensors are not shielded against solar radiation, incoming short-wave radiation 
Table 1. Classification of the weather condition based on synoptic weather observations

\begin{tabular}{|c|c|c|}
\hline & Cyclonic Conditions & Non-cyclonic Conditions \\
\hline \multirow{7}{*}{ Present Weather (ww) } & $20-29 \backslash\{28\}:$ precipitation at the station & 0-19: cloud cover, haze and \\
\hline & during the preceding hour & non-precipitation events \\
\hline & 30-39: blowing and drifting snow & 28: fog at the station \\
\hline & 50-59: drizzle & during the preceding hour \\
\hline & 60-69: rainfall & 40-49: fog and ice fog \\
\hline & $70-79 \backslash\{76,77,78\}:$ solid precipitation & 76-78: diamond dust, snow grains \\
\hline & 80-89: showers & and star like crystals during fog conditions \\
\hline \multirow{5}{*}{ Past Weather (WW) } & 3: blowing snow & \multirow{5}{*}{$\begin{array}{l}0-2 \text { : cloud cover } \\
\text { 4: fog }\end{array}$} \\
\hline & 5: drizzle & \\
\hline & 6: rain & \\
\hline & 7: snow or mixed rain and snow & \\
\hline & 8: showers & \\
\hline
\end{tabular}

can heat the sensors during daytime launches, causing the so-called daytime radiation dry bias. Currently there is no proper correction for issues with sensor icing and therefore they were neither considered. Furthermore, the two earlier types (RS80 and RS90) were tested rather inland under a more extreme environment compared to the near-shore conditions. Since there are no studies assessing the associated impacts in accuracy of these sensors at the Antarctic margin, it is therefore assumed that some bias may still occur, but minimized.

According to Nash et al. (2011), the typical temperature uncertainty for RS92 within the lower troposphere is below $0.1 \mathrm{~K}$. For typical temperature ranges at Neumayer, between 0 and $-40{ }^{\circ} \mathrm{C}$, relative humidity errors are often below $1.5 \%$. However, for values of relative humidity between 60 and $80 \%$, when the air temperature is close to $-50{ }^{\circ} \mathrm{C}$, errors can reach $2 \%$ during day and oscillating from -2 to $2 \%$ during night. The uncertainty associated with air pressure is always lower than $0.05 \mathrm{hPa}$ regardless of the environment circumstance.

\subsection{Definition of weather condition categories}

Since the mechanisms forming temperature and humidity inversions are different for different weather conditions, the radiosonde observations were grouped into "cyclonic" and "non-cyclonic" conditions using the SYNOP code of present (ww) and past weather (WW) based on WMO codes (2016). Basically, cyclonic conditions were defined as observations of significant precipitation or drifting/blowing snow at the time of the observation or in the preceding hour. Non-cyclonic conditions include observations without any significant weather or with fog or diamond dust precipitation, i.e. extremely small ice crystals that form under clear-sky (or high cloud) conditions without cyclonic influence due to radiative cooling of the air (Curry, 1983). Both fog and diamond dust usually occur under quiet conditions with low wind speeds, thus they are included in the 
https://doi.org/10.5194/wcd-2021-22

Preprint. Discussion started: 10 May 2021

(C) Author(s) 2021. CC BY 4.0 License.

Weather and

Climate Dynamics

(c) (i)

non-cyclonic category. If the past weather indicates blowing snow or any sort of precipitation (drizzle, rain or snow) these dates are classified as cyclonic conditions even when the current weather does not show cyclonic influence anymore.

Fog conditions do not necessarily mean more humid conditions close to the surface than the other non-cyclonic conditions, e.g. fog can form in very cold anti-cyclonic weather with low absolute, but high relative humidity. However, fog conditions prevail only for a small percentage of the study period and its small sample does not significantly influence the overall noncyclonic statistics. Table 1 presents the exact SYNOP code numbers defining the classification.

\subsection{Detection of temperature and humidity inversions}

Specific humidity was calculated from the observed temperature, relative humidity and air pressure. The definition and terminology used to define temperature and humidity inversions generally follows that of Andreas et al. 2000, which was also used by Vihma et al. 2011, Kilpeläinen et al. 2012 and Nygård et al. 2013. However, different thresholds were defined. In order to overcome signal noise, we created a 5-point moving average profile solely to detect the inversion base and top positions whereby these positions were used to extract the raw value from the original data set. The difference between the base height $\left(z_{q b}\right)$, where specific humidity starts vertically increasing, and the top height $\left(z_{q t}\right)$, where the specific humidity starts decreasing is the humidity inversion depth $\left(\Delta z_{q}\right)$, which makes $\Delta z_{q}=z_{q t}-z_{q b}$. The difference in specific humidity between the inversion top $\left(q_{t}\right)$ and base $\left(q_{b}\right)$ is the humidity inversion strength $(\Delta \mathrm{q})$, meaning $\Delta q=q_{t}-q_{b}$. Although previous studies seldom consider a humidity strength threshold but only a positive vertical gradient, here, all humidity inversions deeper than $10 \mathrm{~m}$ and stronger than $0.1 \mathrm{~g} \mathrm{~kg}^{-1}$ were detected, in order to avoid artificial inversions generated by sporadic inaccurate measurements related to e.g. dry-bias. Separate inversion layers are considered when there is a layer of negative vertical gradient in between inversion layers deeper than $100 \mathrm{~m}$. Temperature inversions were detected analogously to humidity inversions. Hence, temperature inversion strength is $\Delta T=T_{t}-T_{b}$ and temperature inversion depth is $\Delta z_{T}=z_{T t}-z_{T b}$. However, only for cases where the temperature inversion strength was larger than $1^{\circ} \mathrm{C}$ were of interest. Differences lower than the considered threshold may occur, but regarding their weakness they were ignored.

The upper limit of the lower troposphere is here considered up to $500 \mathrm{hPa}(\sim 5000 \mathrm{~m})$. Since BSRN vertical resolution comprises on average almost 100 vertical levels between the surface and $5000 \mathrm{~m}$, inversions not containing at least one level in between the inversion base and top were considered negligible.

Since the formation mechanisms are different for surface-based and elevated inversions, three different inversion levels of occurrence were defined dependent on inversion base height: surface-based if its base is located below $50 \mathrm{~m}$; second-level inversion if its base lies between 50 and $2500 \mathrm{~m}$; and third-level inversions for all cases with base heights larger than $2500 \mathrm{~m}$. When more than one inversion of the same type exists in a profile, it is called multiple inversion.

\section{Results}

For the time period 1993 - 2017, 8489 radiosonde launches were analyzed. Radiosondes were available for $93 \%$ of the times in a total of 9131 days. $55 \%$ of these days were characterized by cyclonic, $45 \%$ by non-cyclonic conditions (Fig. 2). The most 
https://doi.org/10.5194/wcd-2021-22

Preprint. Discussion started: 10 May 2021

(c) Author(s) 2021. CC BY 4.0 License.

(c) (i)

Weather and

Climate Dynamics

Discussions

frequent cause of a radiosonde launch failure is high wind speeds, as proven by a success rate of $98 \%$ under non-cyclonic vs.

$90 \%$ for cyclonic events.

\subsection{General inversion occurrence}

Note that in order to detect these temperature and humidity inversions, certain thresholds and definitions were applied (Subsection 2.5), which shapes the presented results.

Following those definitions, Figure 2 shows that, overall, $78 \%$ of the profiles exhibit at least one temperature inversion (40 $\%$ under cyclonic, $38 \%$ non-cyclonic conditions). At least one humidity inversion was found in $79 \%$ of the profiles (42\% cyclonic, $37 \%$ non-cyclonic). Temperature and humidity inversions occurred simultaneously in about two thirds of the cases, in almost equal percentages for cyclonic and non-cyclonic conditions. Multiple inversions in a profile are common in all seasons for both weather conditions.

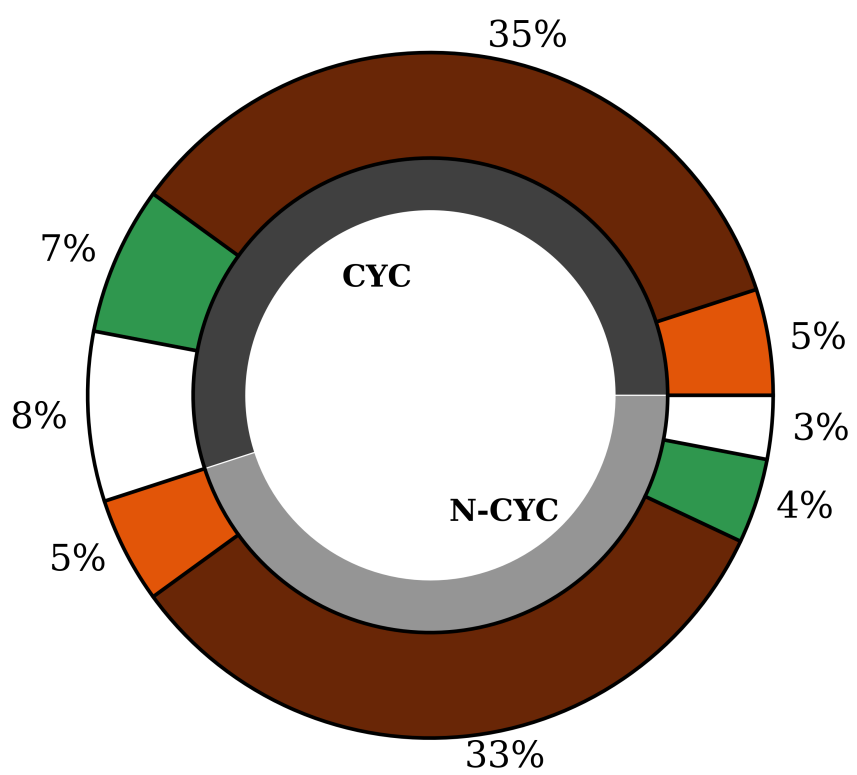

Figure 2. Total percentage of days with temperature (orange), humidity (green), simultaneous (brown) and without (white) inversions for cyclonic (CYC) and non-cyclonic (N-CYC) conditions

In Figure 3 the overall percentages were split for the three different inversion levels. While temperature inversions are most common close to the surface and under non-cyclonic conditions, humidity inversions occur more often under cyclonic conditions at higher levels. At the surface level, temperature inversions are more frequent than humidity inversions for both weather conditions, whereas at upper levels the contrary is found. 
At the second level, while under non-cyclonic conditions a large part of humidity inversions occur alone, for cyclonic conditions they are often associated with temperature inversions.

At the third level, inversions are generally rare and neither inversion type nor simultaneity depends on the weather conditions. For both cyclonic and non-cyclonic conditions, they are always associated with an inversion underneath, most often with one at the second level.

Simultaneously occurring temperature and humidity inversions are mostly found at the surface level for non-cyclonic conditions, whereas for cyclonic conditions they are more frequent at the second level.

a)

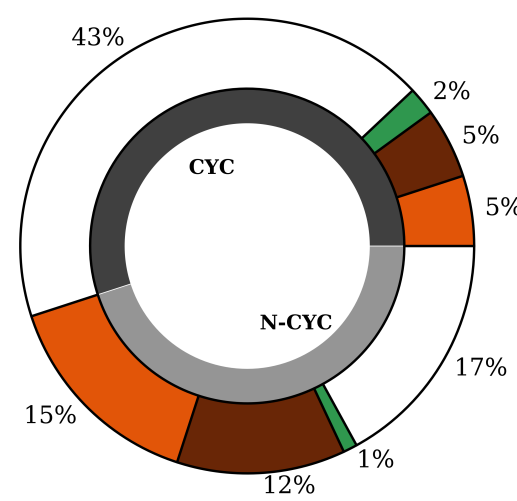

b)

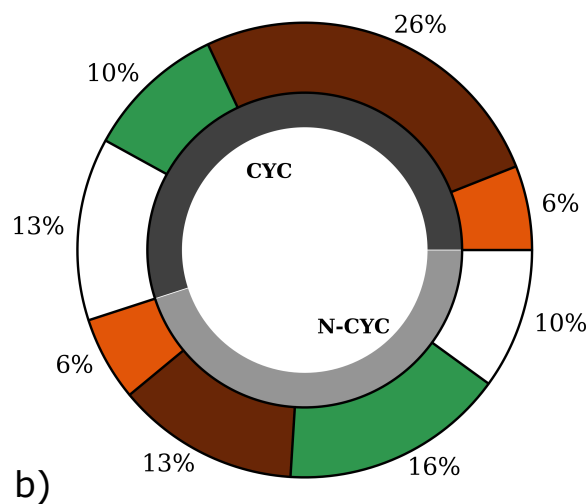

C)

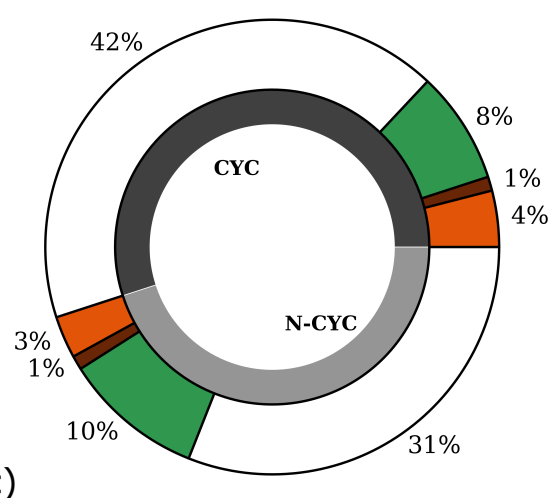

Figure 3. Percentage of days with temperature (orange), humidity (green), simultaneous (brown) and without (white) inversions at the three levels (first level: a; second level: b; third level: c) for cyclonic (CYC) and non-cyclonic (N-CYC) conditions; grey shaded area indicates the percentage of days under the prevailing weather condition

\subsection{Seasonality of inversion occurrence}

In the following, the seasonality of the various features characterizing both temperature and humidity inversions will be investigated. Since we calculate monthly statistics rather than seasonal statistics, we do not define seasons here, however, note that winter in Antarctica usually comprises more than the three months of June, July and August. For coastal stations, which do not exhibit the coreless winter typical for inland locations, a sharp definition of seasons does not seem to make sense since it would vary from year to year. For better flow of reading we preferred to use the word winter in the discussion rather than always specifying certain ranges of months.

In Figure 4, the monthly distribution of temperature and humidity inversion occurrence is shown for the three levels defined in Subsection 2.5 under cyclonic and non-cyclonic conditions. Supplementary Figures 1 and 2 are available in the appendix for a detailed view of the monthly distribution of days with temperature and humidity inversions.

The box contains all data between the $25^{t h}$ and $75^{t h}$ percentiles, separated by the median. As many of these variables are not normally distributed and likely to be affected by outliers, both mean and median values are displayed. Whiskers mark the 
https://doi.org/10.5194/wcd-2021-22

Preprint. Discussion started: 10 May 2021

(C) Author(s) 2021. CC BY 4.0 License.

(c) (i)
Weather and

Climate Dynamics

Discussions

limits of the lower and upper inner fence, defined as $1.5 \mathrm{IQR}$ beyond the $25^{\text {th }}$ and $75^{\text {th }}$ percentiles, respectively. Outliers are defined as values outside the lower (upper) inner fence and marked individually.

At the surface level, generally temperature inversions are more frequent than humidity inversions. Both have a clear seasonal cycle with a minimum in summer and maximum in winter. This cycle is more pronounced for non-cyclonic than for cyclonic conditions, the latter generally showing higher variability of occurrence. In all seasons, more inversions occur under noncyclonic (Fig. 4d) than under cyclonic conditions (Fig. 4a) at this level; in summer hardly any inversions are seen under non-cyclonic conditions.

Contrary to the surface level, the second level exhibits more humidity inversions than temperature inversions and the inversion occurrence is higher for cyclonic (Fig. 4b) than for non-cyclonic conditions (Fig. 4e). Under non-cyclonic conditions, variability of occurrence is high and no clear seasonal cycle is found here, whereas for cyclonic conditions maxima are seen in spring and fall, which are the seasons with the highest cyclonic activity.

At the third level, inversion occurrence is considerably lower than at the other two levels, with a mostly weak annual cycle that exhibits a minimum in winter. Only for humidity inversions under non-cyclonic conditions (Fig. 4f) a strong annual cycle can be seen that is contrary to the annual cycle at the surface, i.e. a maximum of occurrence in summer and a minimum in winter. 


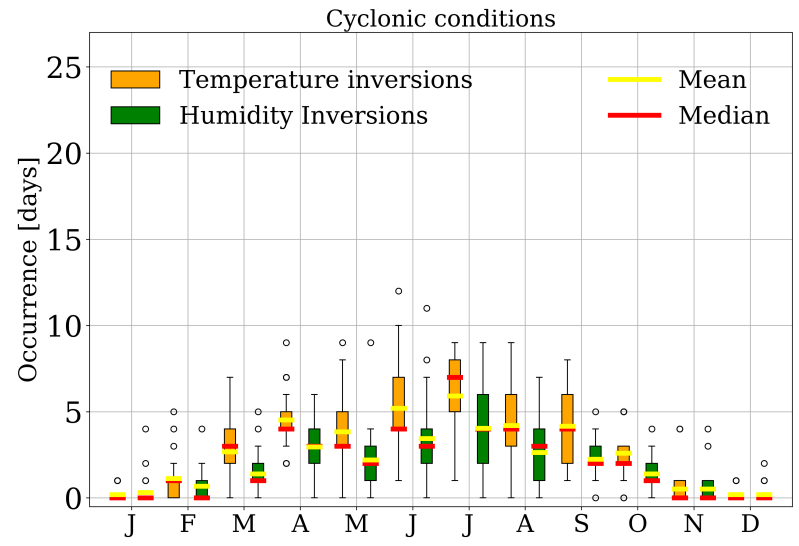

a)

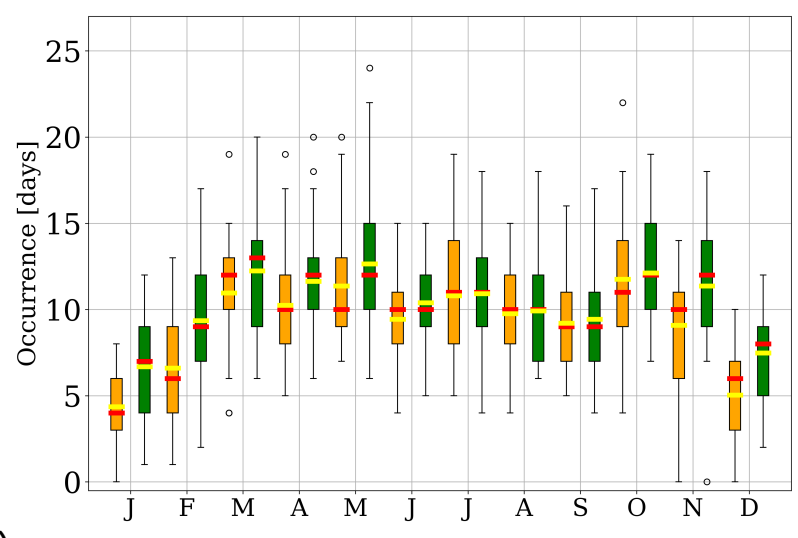

b)

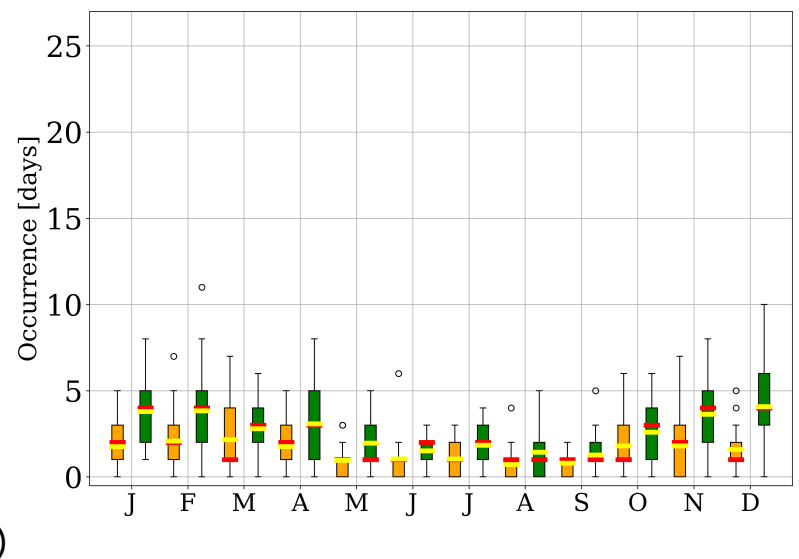

d)
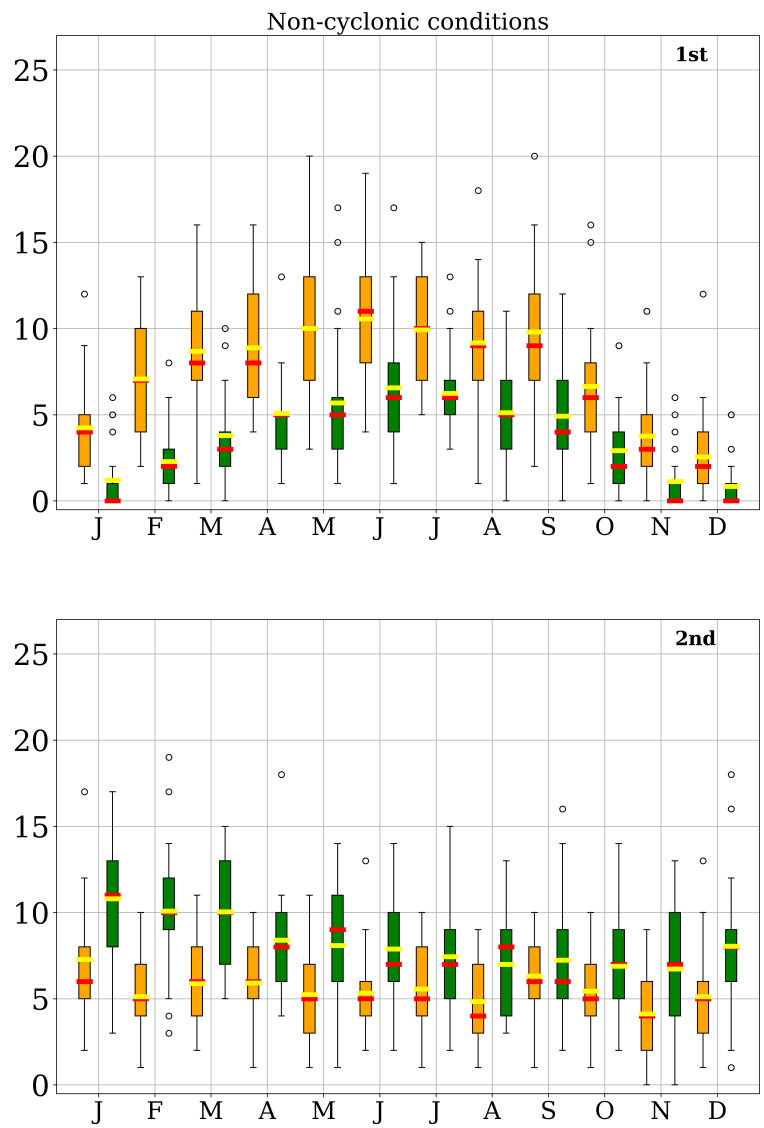

e)

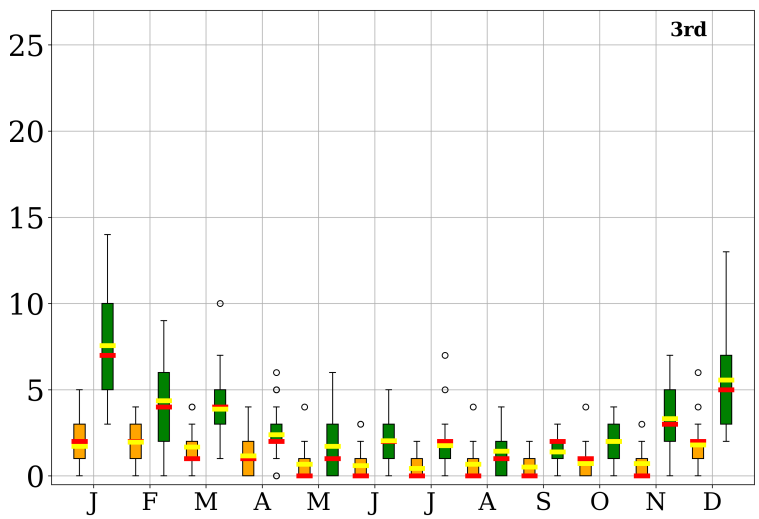

f)

Figure 4. Monthly mean (yellow) and median (red) inversion occurrence (number of days with inversion) at the three different levels (first level: a and d; second level: $\mathrm{b}$ and e; third level: $\mathrm{c}$ and f) for cyclonic (a,b,c) and non-cyclonic (d,e,f) conditions. 
https://doi.org/10.5194/wcd-2021-22

Preprint. Discussion started: 10 May 2021

(C) Author(s) 2021. CC BY 4.0 License.

(c) (i)

Weather and

Climate Dynamics

Discussions

\subsection{Seasonality of temperature-inversion features}

The monthly distribution of temperature inversion occurrence is intrinsically related to the monthly temperature inversion features, i.e. strength $(\Delta \mathrm{T})$, depth $\left(\Delta \mathrm{Z}_{T}\right)$ and vertical temperature gradient $(\Delta \mathrm{T} / \Delta \mathrm{z})$, which are shown in Figures 5,6 and 7 , 245 respectively. 
a)
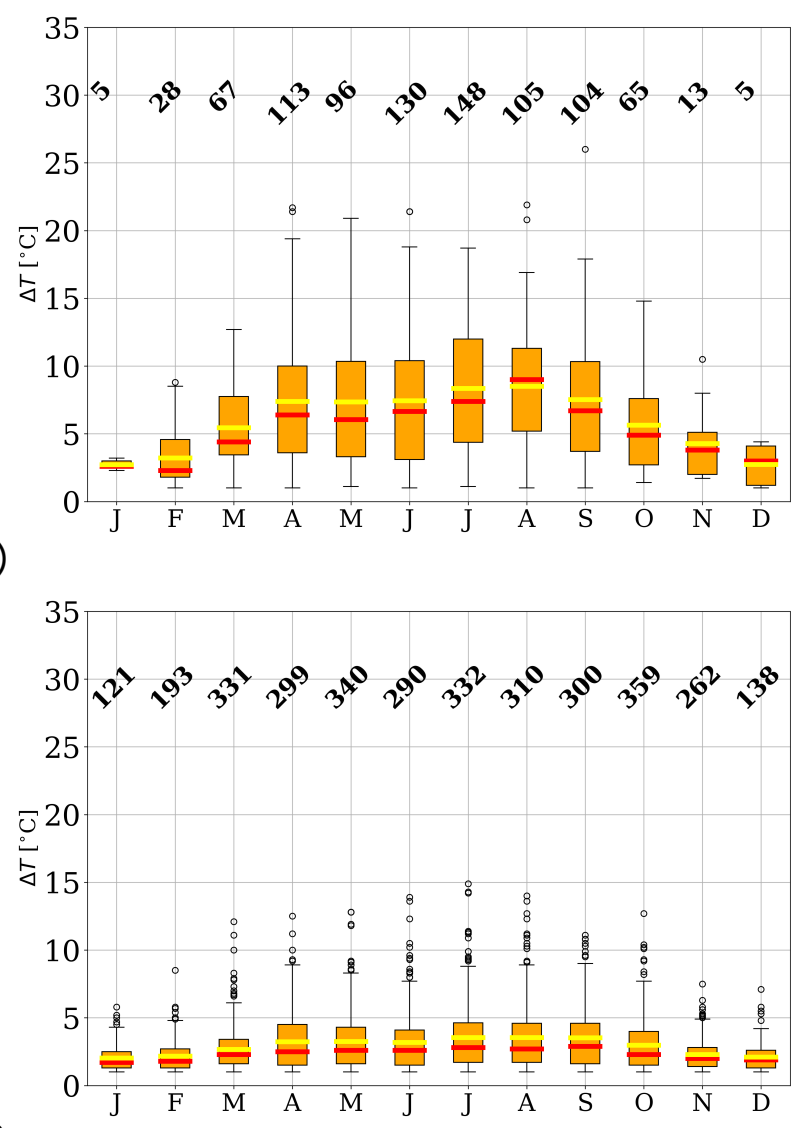

b)

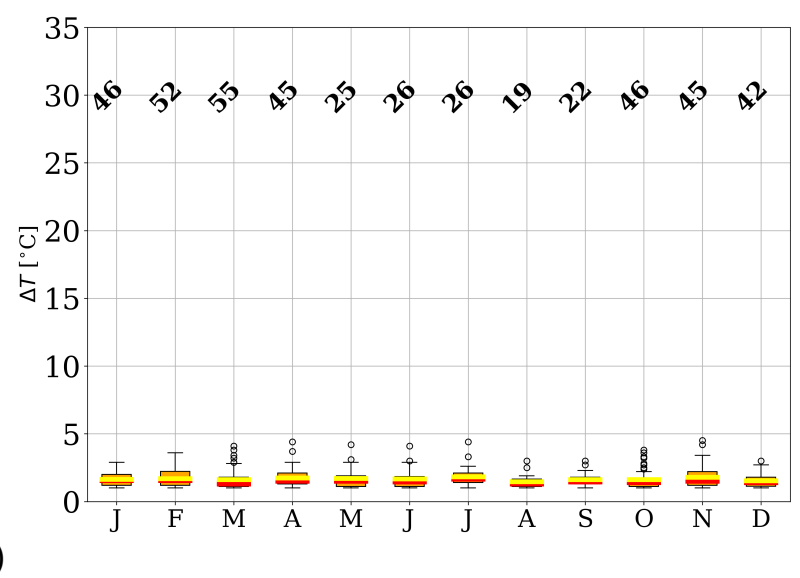

c) d)
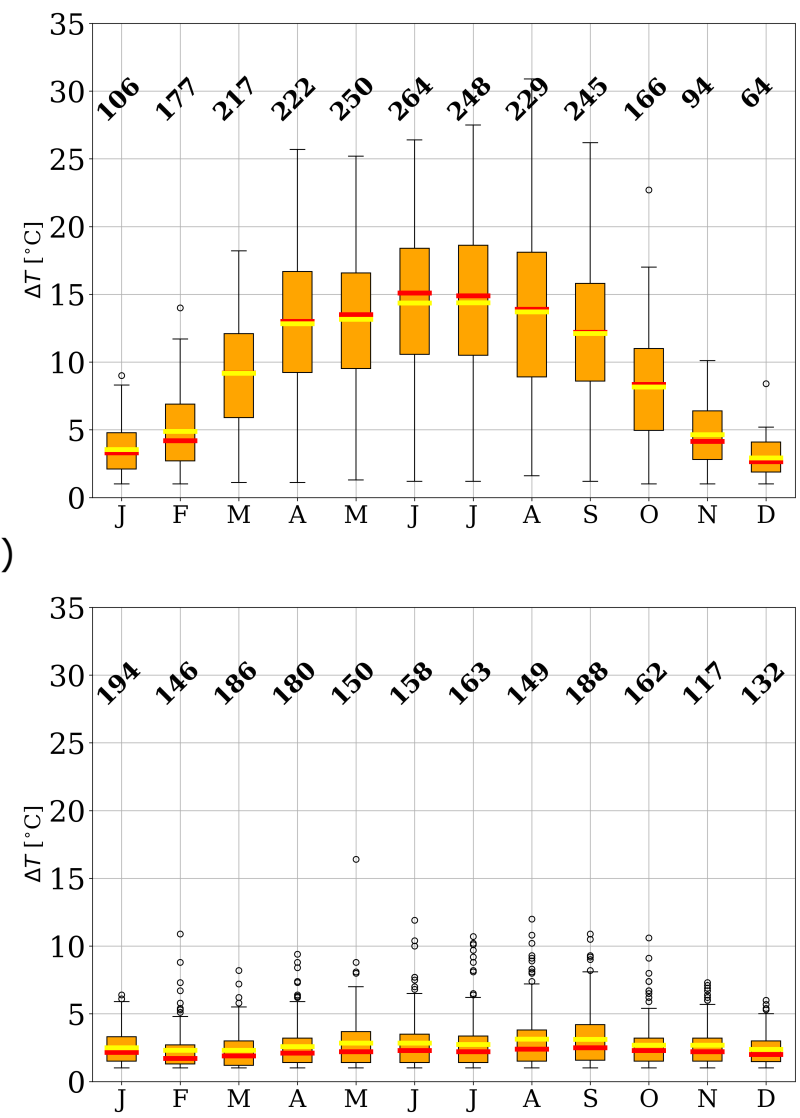

e)

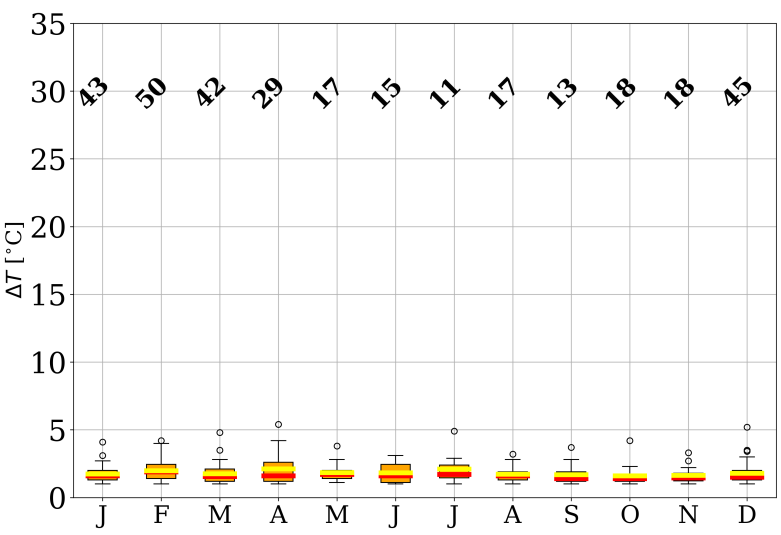

Figure 5. Monthly mean (yellow) and median (red) temperature inversion strength at the three different levels (first level: a and d; second level: $b$ and e; third level: $\mathrm{c}$ and $\mathrm{f}$ ) for cyclonic $(\mathrm{a}, \mathrm{b}, \mathrm{c})$ and non-cyclonic $(\mathrm{d}, \mathrm{e}, \mathrm{f})$ conditions; numbers at the top of each subplot indicate the monthly sample size 
https://doi.org/10.5194/wcd-2021-22

Preprint. Discussion started: 10 May 2021

(C) Author(s) 2021. CC BY 4.0 License.

(c) (i)
Weather and

Climate Dynamics

Discussions

In Figure 5, temperature inversion strength for the three levels and two weather conditions is displayed. Surface-based inversions show a clear annual cycle with a winter maximum. The cycle is stronger and clearer for non-cyclonic conditions (Fig. 5d). Here in winter, values up to $25^{\circ} \mathrm{C}$ can be reached, whereas under cyclonic conditions (Fig. 5a) the strength of inversions seldom exceeds $15^{\circ} \mathrm{C}$. The difference between mean and median values is smaller for non-cyclonic conditions because generally higher values with less extreme outliers occur.

At the second level, inversions are considerably weaker than at the surface level, and only a very weak annual cycle shaped by outliers is found for cyclonic conditions (Fig. 5b) with a winter maximum, whereas for non-cyclonic conditions (Fig. 5e) no annual cycle is seen. In contrast to the surface-based inversions, cyclonic inversions are slightly stronger than non-cyclonic ones, particularly in fall and winter. Only in summer, the non-cyclonic inversions are slightly stronger than cyclonic inversions, whereas in winter the opposite is the case. Generally, strength differences between the two weather conditions are almost imperceptible. The mean value is slightly higher than the median for both conditions in all seasons due to numerous outliers. The third level exhibits only very weak inversions, with no annual cycle, independent of the weather conditions. 


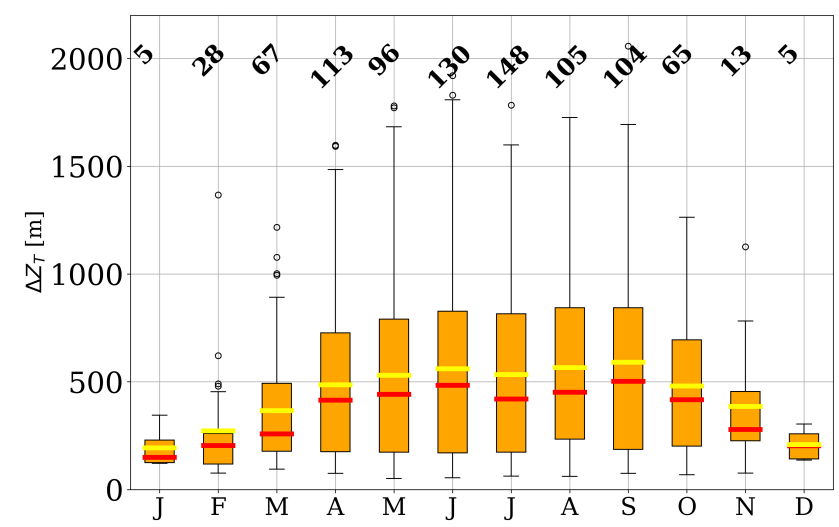

a)

d)
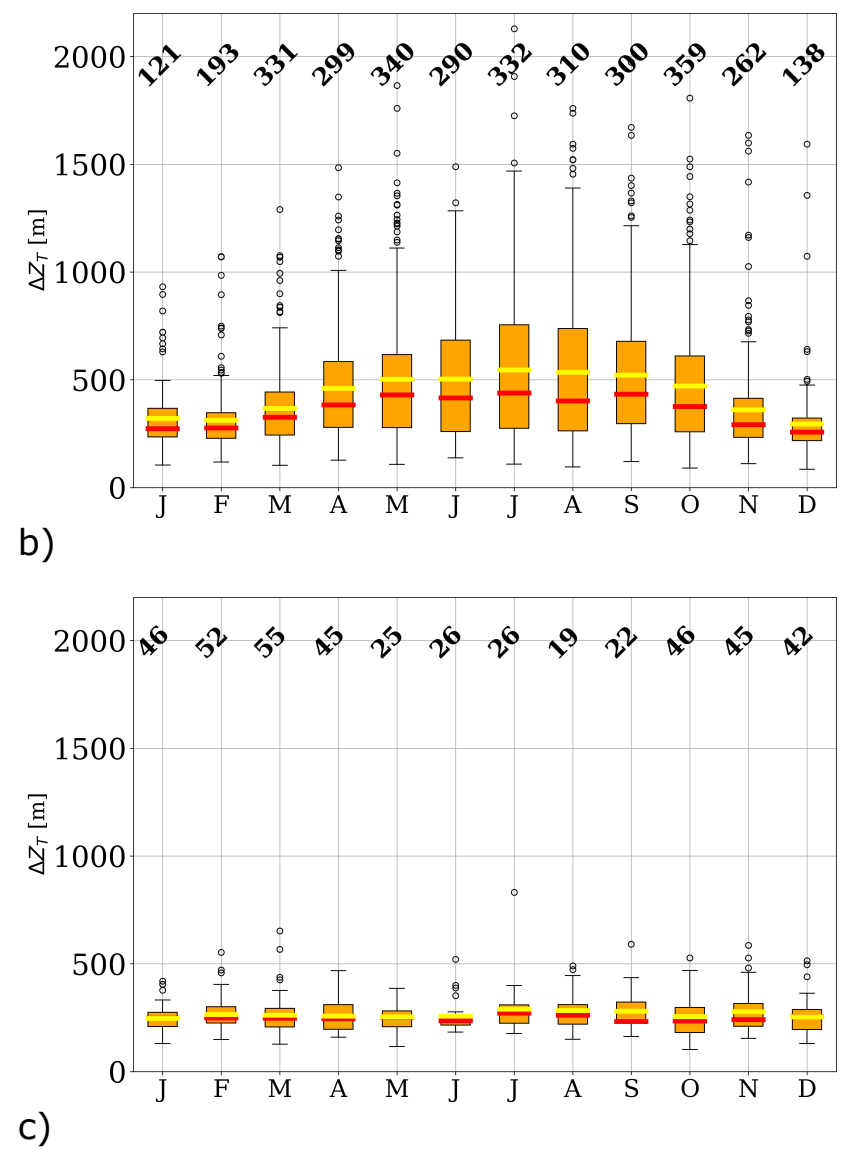
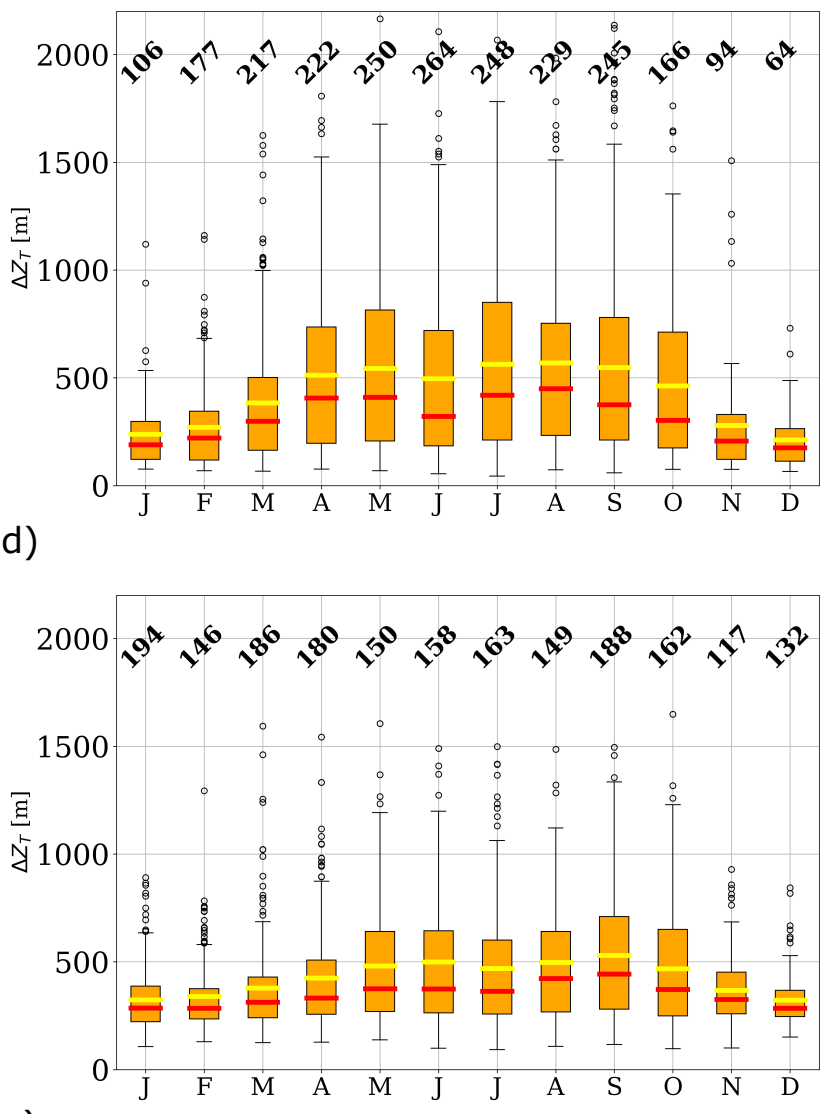

e)

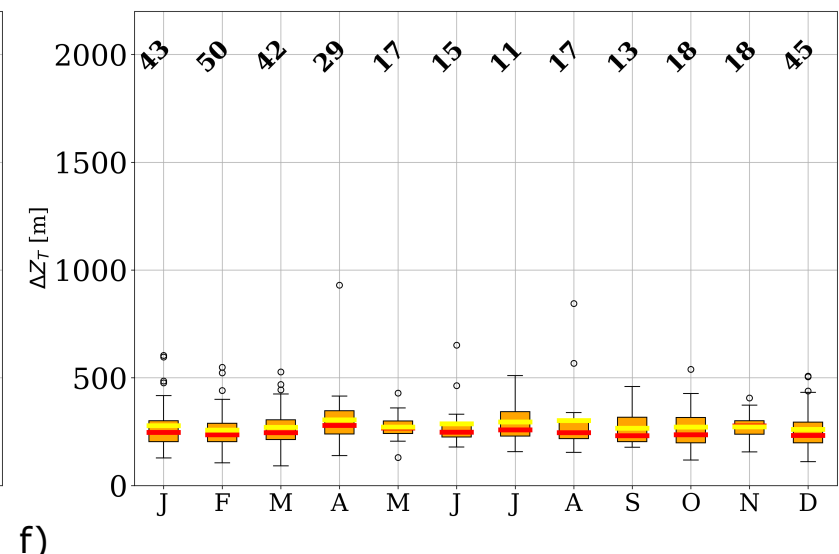

Figure 6. Monthly mean (yellow) and median (red) temperature inversion depth at the three different levels (first level: a and d; second level: b and e; third level: $c$ and f) for cyclonic (a,b,c) and non-cyclonic (d,e,f) conditions; numbers at the top of each subplot indicate the monthly sample size 
https://doi.org/10.5194/wcd-2021-22

Preprint. Discussion started: 10 May 2021

(c) Author(s) 2021. CC BY 4.0 License.

(c) (1)

Weather and

Climate Dynamics

Discussions

Inversion depth is displayed in Figure 6. Surface-based inversions show a relatively clear annual cycle with maxima in the polar night and no striking differences between the two weather conditions. During long, cold periods, non-cyclonic conditions (6d) can lead to inversions deeper than $2000 \mathrm{~m}$. Those untypically thick temperature inversions are reflected in the large number of upper outliers, which leads to a difference between median and mean values of up to several hundred meters.

At the second level, inversions are generally less deep, thus the annual cycle is less pronounced. However, variability of inversion depth seems to be very high, which is demonstrated by the larger number of outliers for both weather conditions throughout the year.

265 Third-level inversions are, with an approximate depth of $200 \mathrm{~m}$, generally shallow and exhibit no annual cycle. They are on average found at heights above $3200 \mathrm{~m}$ and are independent on the weather conditions. 

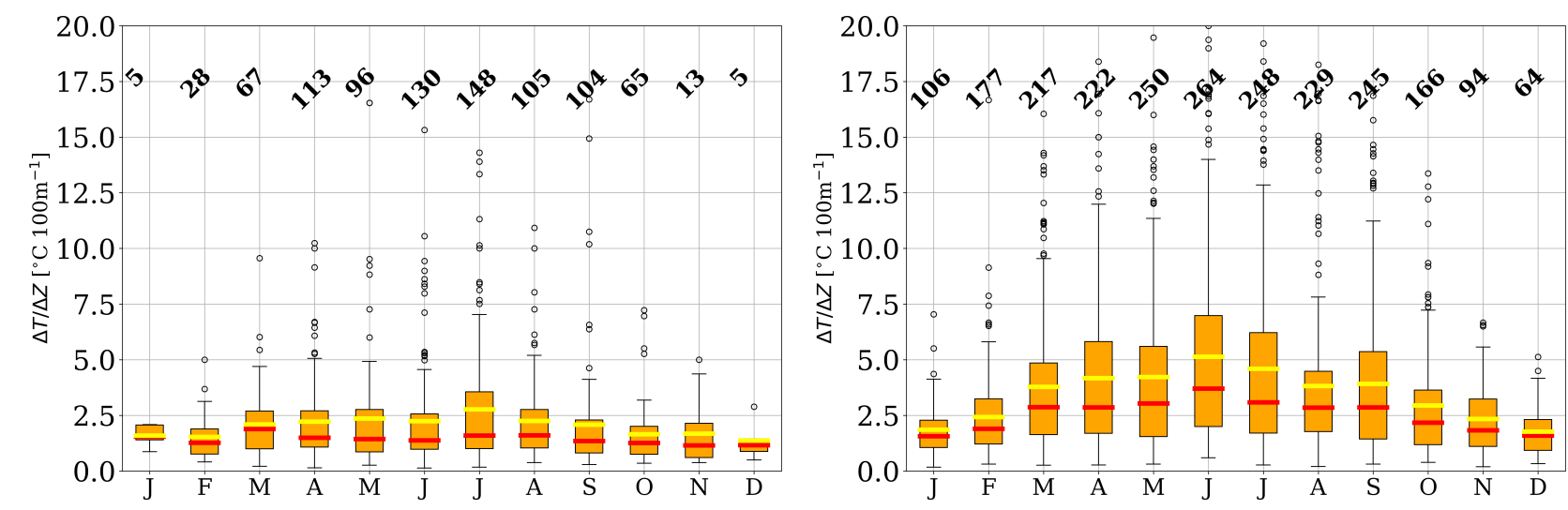

a)

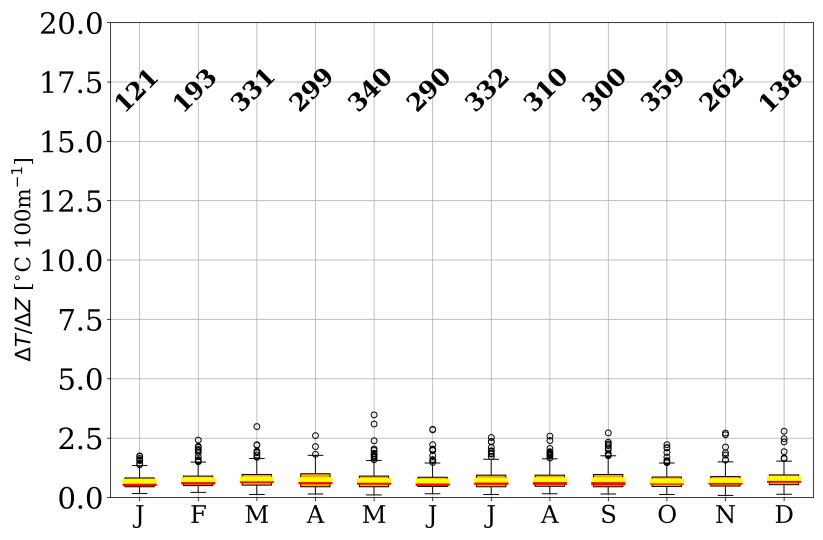

b)

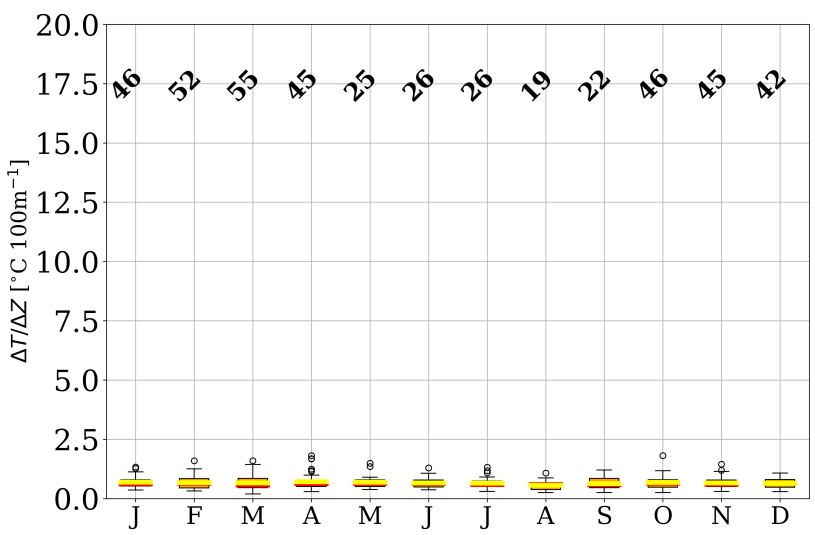

c)

d)

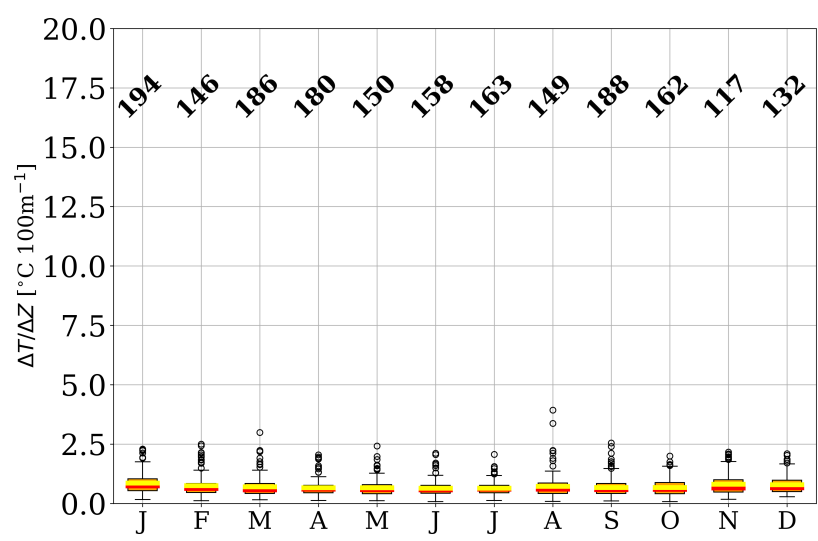

e)

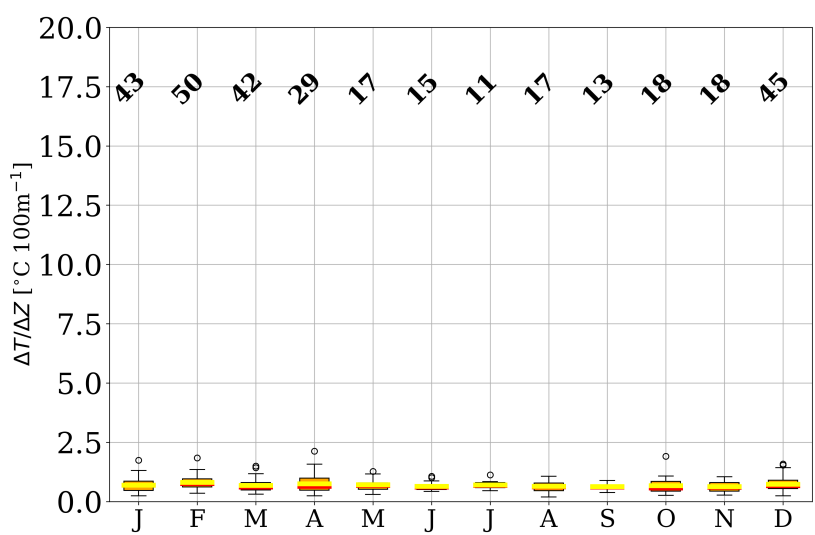

f)

Figure 7. Monthly mean (yellow) and median (red) temperature inversion vertical gradient at the three different levels (first level: a and d; second level: $\mathrm{b}$ and e; third level: $\mathrm{c}$ and f) for cyclonic (a,b,c) and non-cyclonic (d,e,f) conditions;numbers at the top of each subplot indicate the monthly sample size. 
https://doi.org/10.5194/wcd-2021-22

Preprint. Discussion started: 10 May 2021

(C) Author(s) 2021. CC BY 4.0 License.

(c) (i)
Weather and

Climate Dynamics

Discussions

In Figure 7, the vertical gradient for temperature inversions at the corresponding level and weather conditions is shown. Highest gradients are found for surface-based inversions under non-cyclonic conditions (Fig. 7b), where in winter values can reach up to $20^{\circ} \mathrm{C}\left(100 \mathrm{~m}^{-1}\right)$. Minimum values are found in summer for both weather conditions; the vertical gradients are one order of magnitude smaller than in winter. A general, slightly irregular annual cycle, however, is only found for non-cyclonic conditions. A high number of outliers for almost all months for both weather conditions explains the relatively large differences between mean and median vertical temperature gradients, where the mean is always higher than the median.

At the second and the third level, vertical temperature gradients are generally low and almost constant throughout the year, with values of approximately $0.6{ }^{\circ} \mathrm{C}\left(100 \mathrm{~m}^{-1}\right)$. Generally, values hardly vary more than $2{ }^{\circ} \mathrm{C}\left(100 \mathrm{~m}^{-1}\right)$ throughout the year.

275 Note that although inversions at the third level are considerably less deep than those at the second level, vertical gradients are similar at both levels because inversion strength at the third level is generally low, too.

\subsection{Seasonality of humidity-inversion features}

Humidity and temperature inversions are not always related and the mechanisms causing strong temperature inversions are unlikely to be the same as those forming strong humidity inversions. Figures 8, 9 and 10 present the monthly humidity inversion strength $(\Delta \mathrm{q})$, depth $\left(\Delta \mathrm{z}_{q}\right)$ and vertical gradient $(\Delta \mathrm{q} / \Delta \mathrm{Z})$, respectively. 


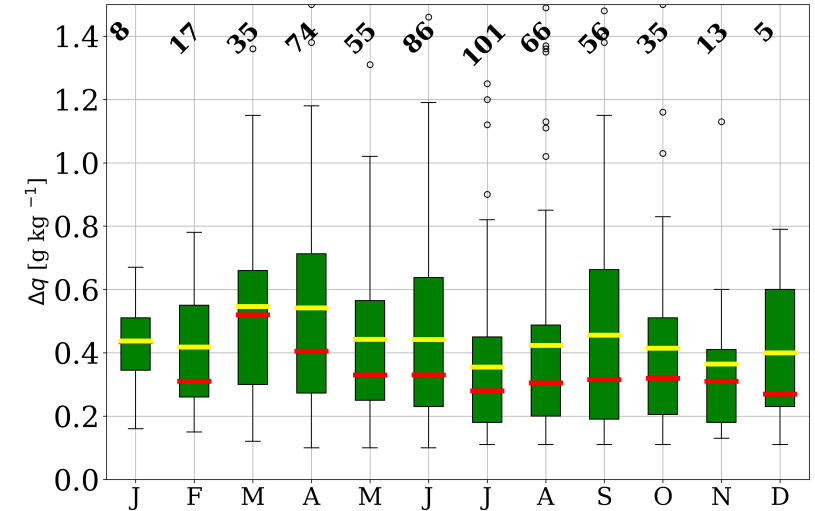

a)

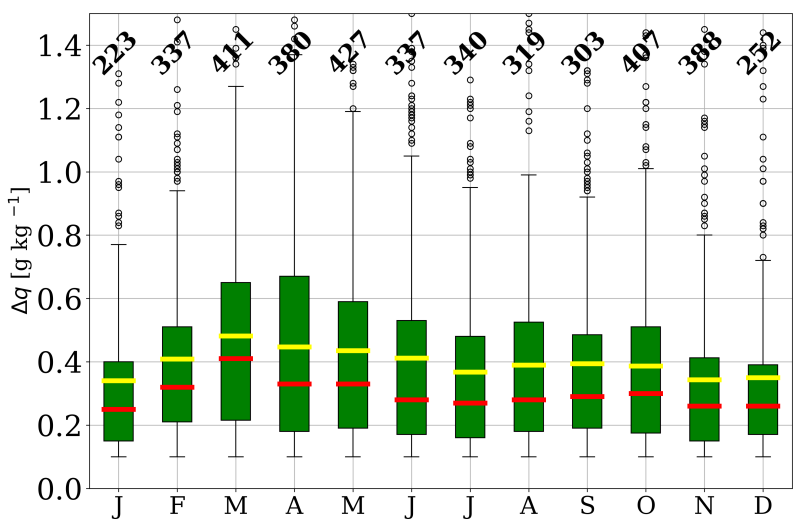

b)

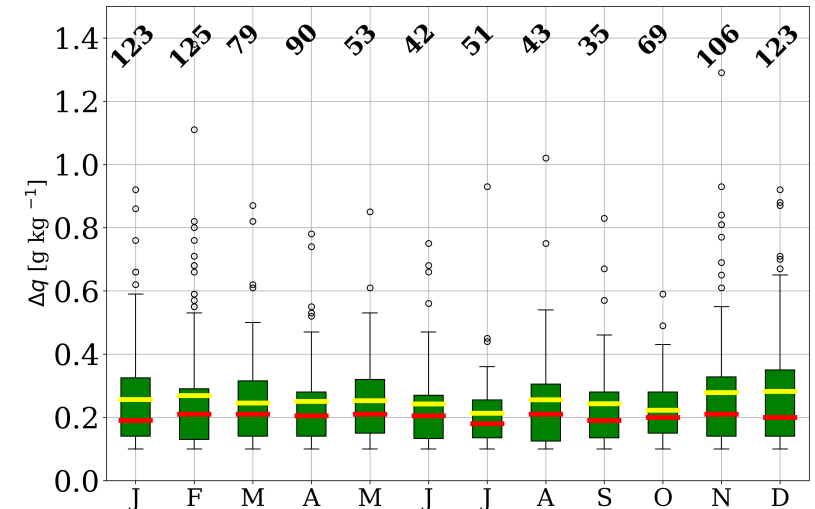

c)

f)

d)

e)
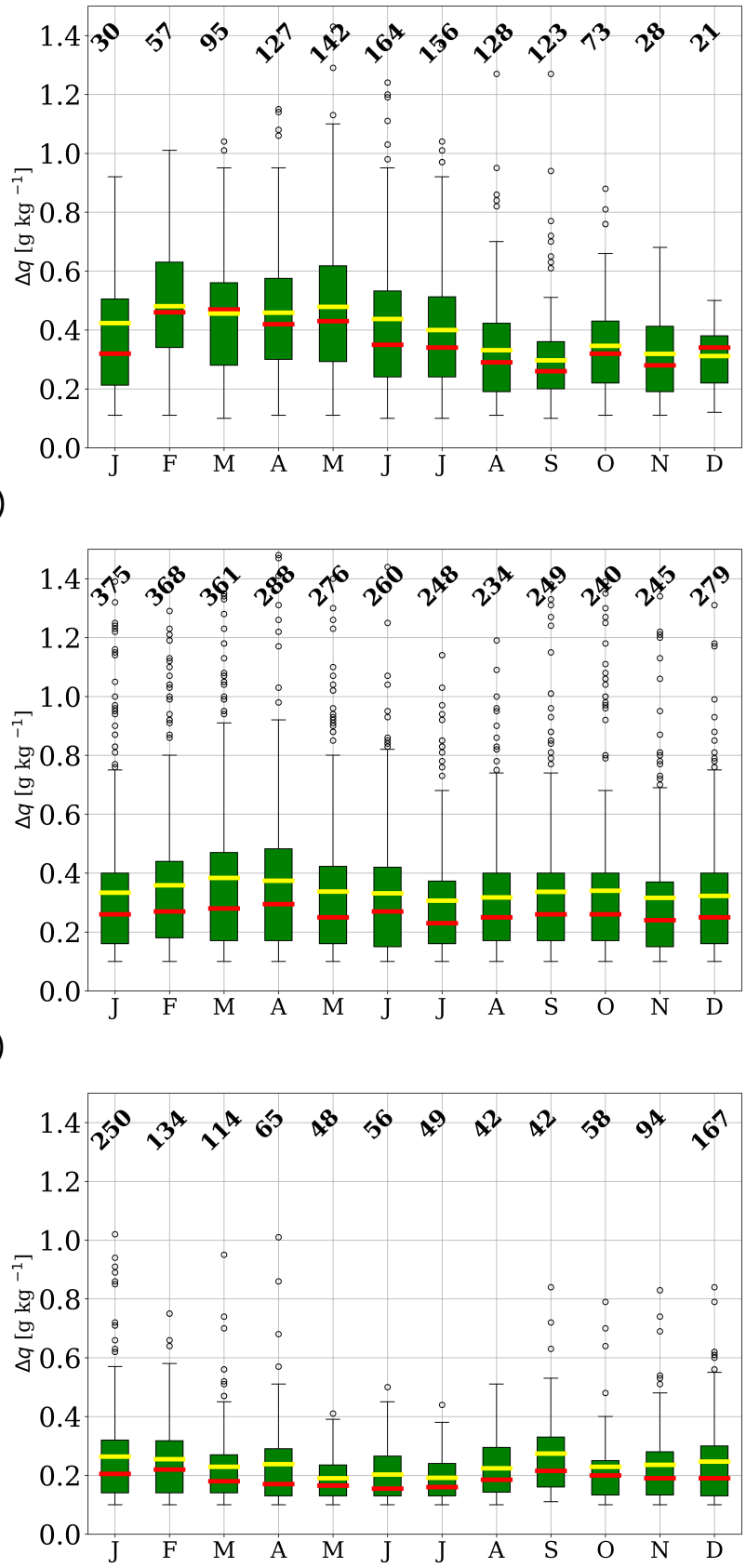

Figure 8. Monthly mean (yellow) and median (red) humidity inversion strength at the three different levels (first level: a and d; second level: $\mathrm{b}$ and e; third level: $\mathrm{c}$ and f) for cyclonic $(\mathrm{a}, \mathrm{b}, \mathrm{c})$ and non-cyclonic $(\mathrm{d}, \mathrm{e}, \mathrm{f})$ conditions; numbers at the top of each subplot indicate the monthly sample size 
https://doi.org/10.5194/wcd-2021-22

Preprint. Discussion started: 10 May 2021

(C) Author(s) 2021. CC BY 4.0 License.

(c) (i)
Weather and

Climate Dynamics

Discussions

Humidity inversion strength generally shows a very high variability for both cyclonic and non-cyclonic conditions and at all levels. Contrary to temperature inversions, at the surface, cyclonic and non-cyclonic inversions have similar strength. Also the first and the second level show similar values (approximately between 0.2 and $0.7 \mathrm{~g} \mathrm{~kg}^{-1}$ ), but the distribution over the year is more even at the second level. Particularly for cyclonic conditions (Fig. 8b) there seems to be a minimum in summer and a relatively clear maximum in fall, whereas for non-cyclonic conditions (Fig. 8e) only a weak maximum in fall and generally much lower variability over the year than at the surface level can be seen. Fall maxima also occur at the surface level, however, variability is so large here that it is not possible to define a distinguished peak. The numerous outliers demonstrate that humidity inversions at the second level can be stronger than at the surface, and they can be equally strong for both weather conditions. Whereas humidity inversions have similar strength for both weather conditions, specific humidity is always higher under cyclonic conditions.

At the third level, similar to temperature inversions, humidity inversions are mostly weak (approximately $0.2 \mathrm{~g} \mathrm{~kg}^{-1}$ ) and no clear annual cycle or difference between the two weather conditions is found. However, occasionally, even at this high level, inversion strengths similar to those at the surface can occur. 


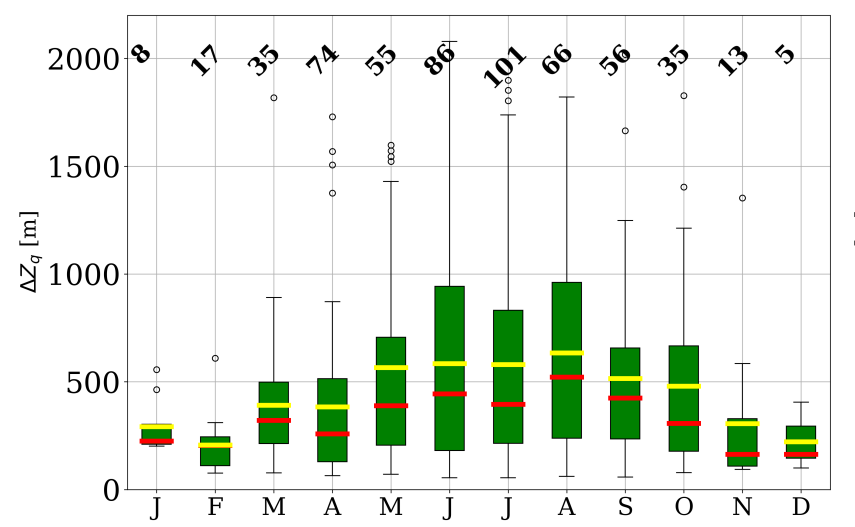

a)

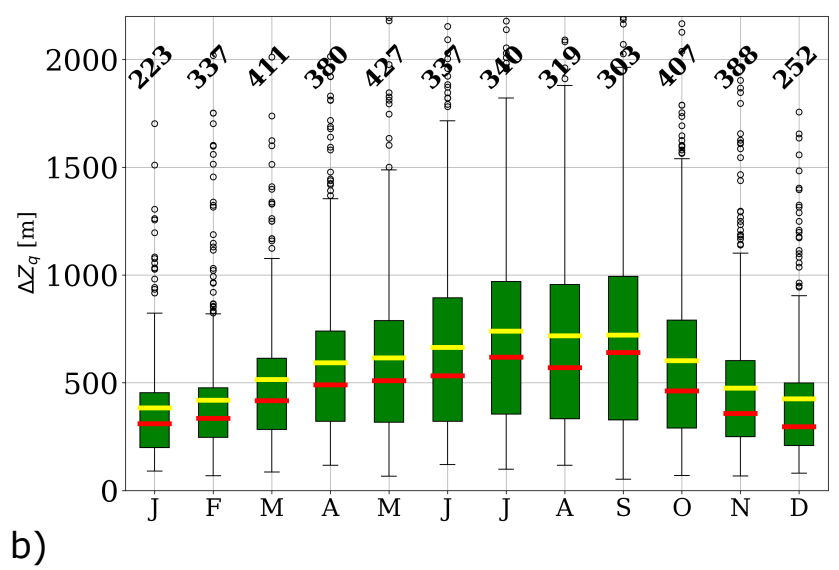

d)
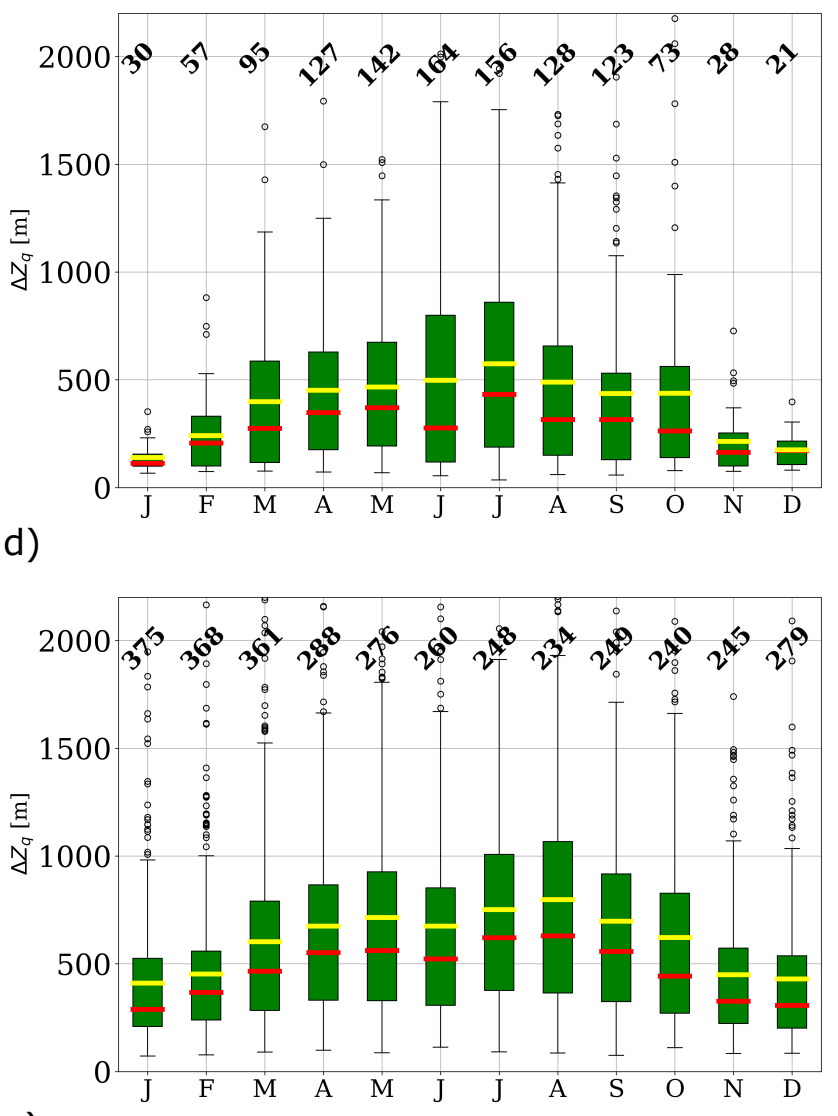

e)

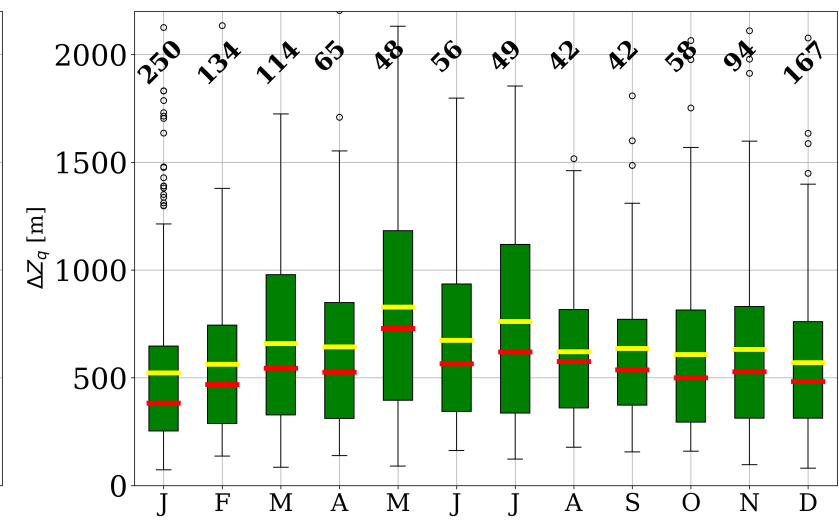

c)

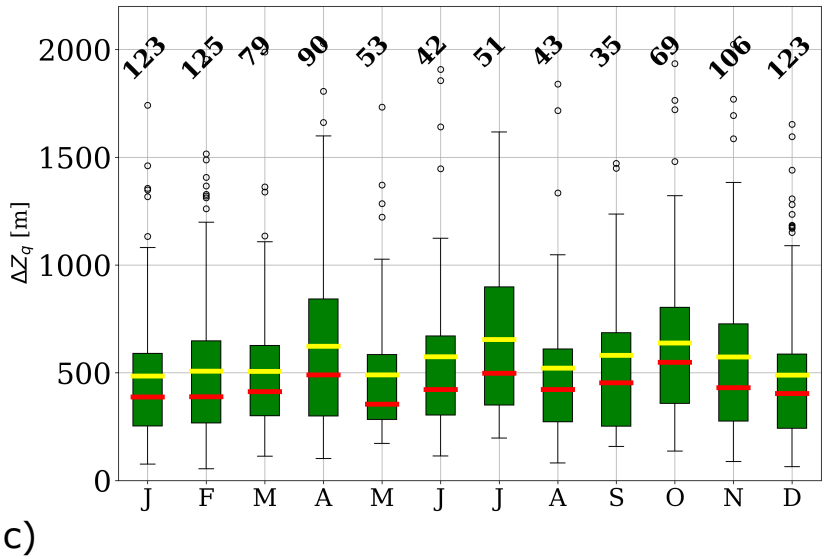

f)

Figure 9. Monthly mean (yellow) and median (red) humidity inversion depth at the three different levels (first level: a and d; second level: b and e; third level: $\mathrm{c}$ and f) for cyclonic $(\mathrm{a}, \mathrm{b}, \mathrm{c})$ and non-cyclonic $(\mathrm{d}, \mathrm{e}, \mathrm{f})$ conditions; numbers at the top of each subplot indicate the monthly sample size 
https://doi.org/10.5194/wcd-2021-22

Preprint. Discussion started: 10 May 2021

(c) Author(s) 2021. CC BY 4.0 License.

(c) (1)

Weather and

Climate Dynamics

Discussions

Humidity inversion depth (Fig. 9) shows a clear annual cycle with winter maxima and summer minima at the first and second level for both weather conditions, which is similar to the annual cycle of temperature inversions. However, in strong contrast to temperature inversions, humidity inversions at the third level have depths similar to the two other levels and, at both upper levels, humidity inversions are deeper than the corresponding temperature inversions, independent of the weather condition. No clear annual cycle is found at the third level. 

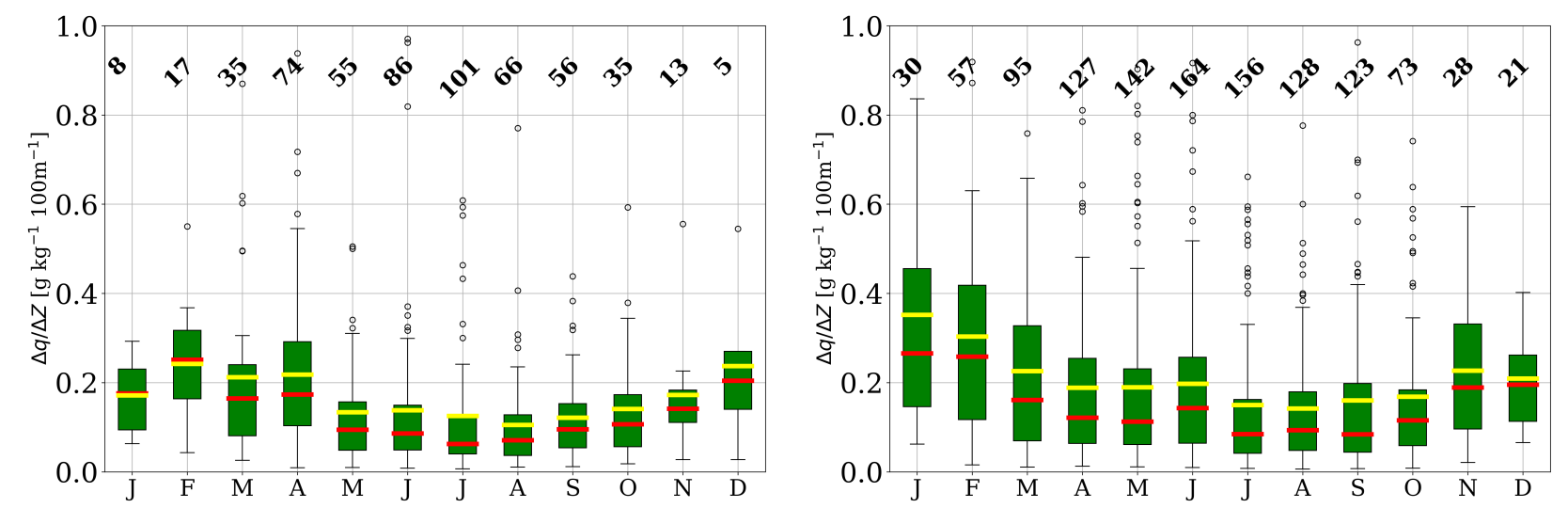

a)
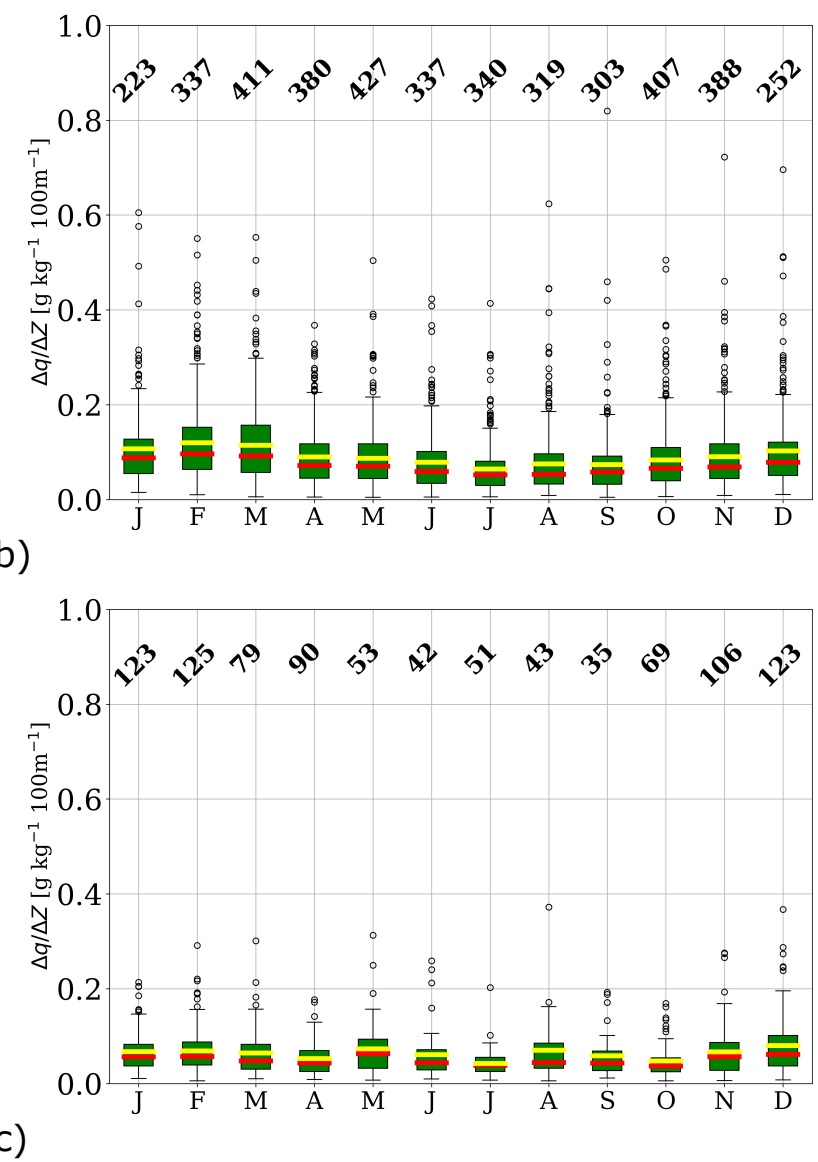

d)

e)

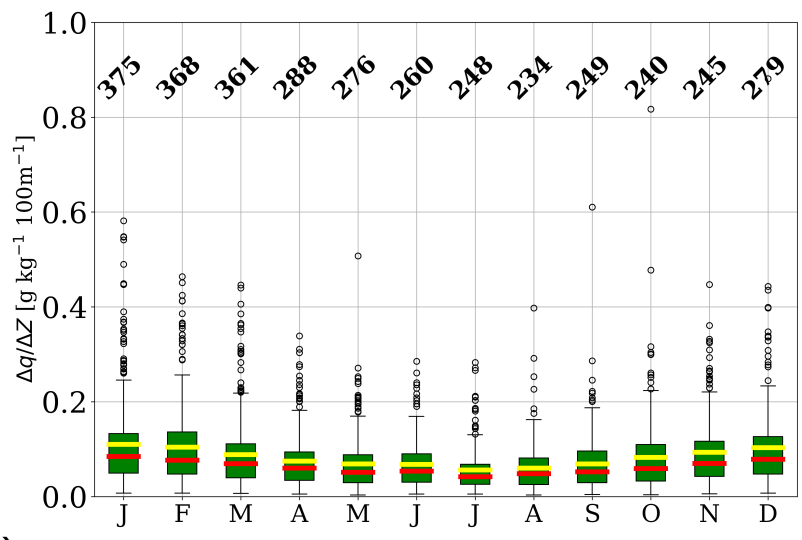

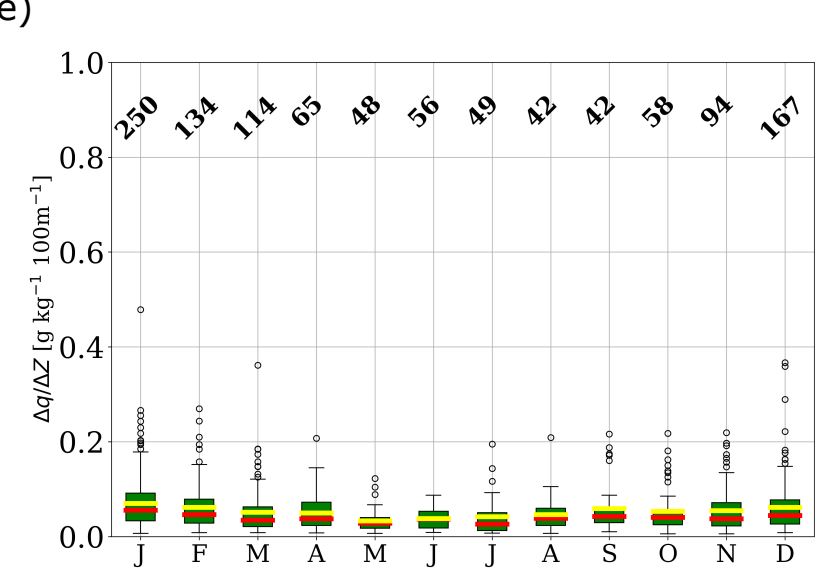

f)

Figure 10. Monthly mean (yellow) and median (red) humidity inversion vertical gradients rate at the three different levels (first level: a and $\mathrm{d}$; second level: $\mathrm{b}$ and e; third level: $\mathrm{c}$ and f) for cyclonic (a,b,c) and non-cyclonic (d,e,f) conditions; numbers at the top of each subplot indicate the monthly sample size 
https://doi.org/10.5194/wcd-2021-22

Preprint. Discussion started: 10 May 2021

(c) Author(s) 2021. CC BY 4.0 License.

(c) (i)

Weather and

Climate Dynamics

Discussions

The vertical humidity gradient (Fig. 10), similar to temperature, shows high values at the surface level, whereas elevated humidity inversions exhibit fairly low gradients. The annual cycle is opposite to the cycle for temperature inversions, with maxima in summer and minima in winter for both weather conditions. Higher values occur for non-cyclonic conditions (Fig. 10d), particularly in summer, where also variability is highest, though.

At the second level, general low values with a weak annual cycle are found, and at the third level it cannot be detected anymore. The large inversion depth combined with moderate to low strength leads to the fairly low vertical gradient, with values mostly below $0.1 \mathrm{~g} \mathrm{~kg}^{-1}\left(100 \mathrm{~m}^{-1}\right)$. Different from temperature inversions, humidity inversion strength, depth, and vertical gradient have rather different annual cycles. A strong humidity inversion is not necessarily also a deep inversion. Note that absolute values of vertical gradients are comparatively small in winter because of the low saturation vapour pressure.

\subsection{Monthly composite profiles}

Mean monthly vertical profiles of temperature and humidity were analyzed up to $2500 \mathrm{~m}$, thus including surface-based inversions and inversions at the second level. In order to calculate the mean vertical profiles, all atmospheric profiles containing at least one inversion at the corresponding level were isolated from the main data set and re-sampled in intervals of $50 \mathrm{~m}$. Missing values were calculated by linear interpolation. These profiles were divided into 12 monthly subsets to produce monthly composites for both weather conditions. These composites together with the corresponding vertical wind profiles are shown in Figures 11 and 12 for temperature and 13 and 14 for humidity inversions. The shaded areas correspond to the range between the $25 \%$ and $75 \%$ percentile. The mean monthly wind vector is displayed in intervals of $100 \mathrm{~m}$. We restrict the height to 2500 $\mathrm{m}$ since, at the third level, inversions are so weak that they are not visible in mean (median) profiles.

The composite temperature profiles for days with surface inversions (Fig. 11) and for days with inversions at the second level (Fig. 12) for both cyclonic (a) and non-cyclonic (b) conditions are displayed together with the the mean monthly wind vector. Note that those divisions are not exclusive, i.e. days with surface-based inversions can have inversions at the second level, too, and vice versa. The numbers of cases are given in the lower left corner for each month.

For surface-based inversions our earlier results are confirmed by the monthly profiles, the inversions are generally seen in the monthly mean, they are stronger in winter than in summer and also stronger for non-cyclonic than for cyclonic condition. Median and mean values are almost identical, except for cyclonic conditions in summer, where inversion depth and strength is generally smallest so that the influence of outliers on the mean is largest.

Winds are mostly weak and come from an easterly (southerly) direction under cyclonic (non-cyclonic) influence. The cases with inversions under cyclonic conditions are usually at the beginning or, more often, at the end of a cyclonic weather situation, following our definition (Subsection 2.5), where the weather between the actual SYNOP observation and the precedent observation is taken into account, too. Whereas a few precipitation events per year occur without strong winds, usually under the influence of a passing cyclone wind speeds considerably increase and surface-based inversions are destroyed. 

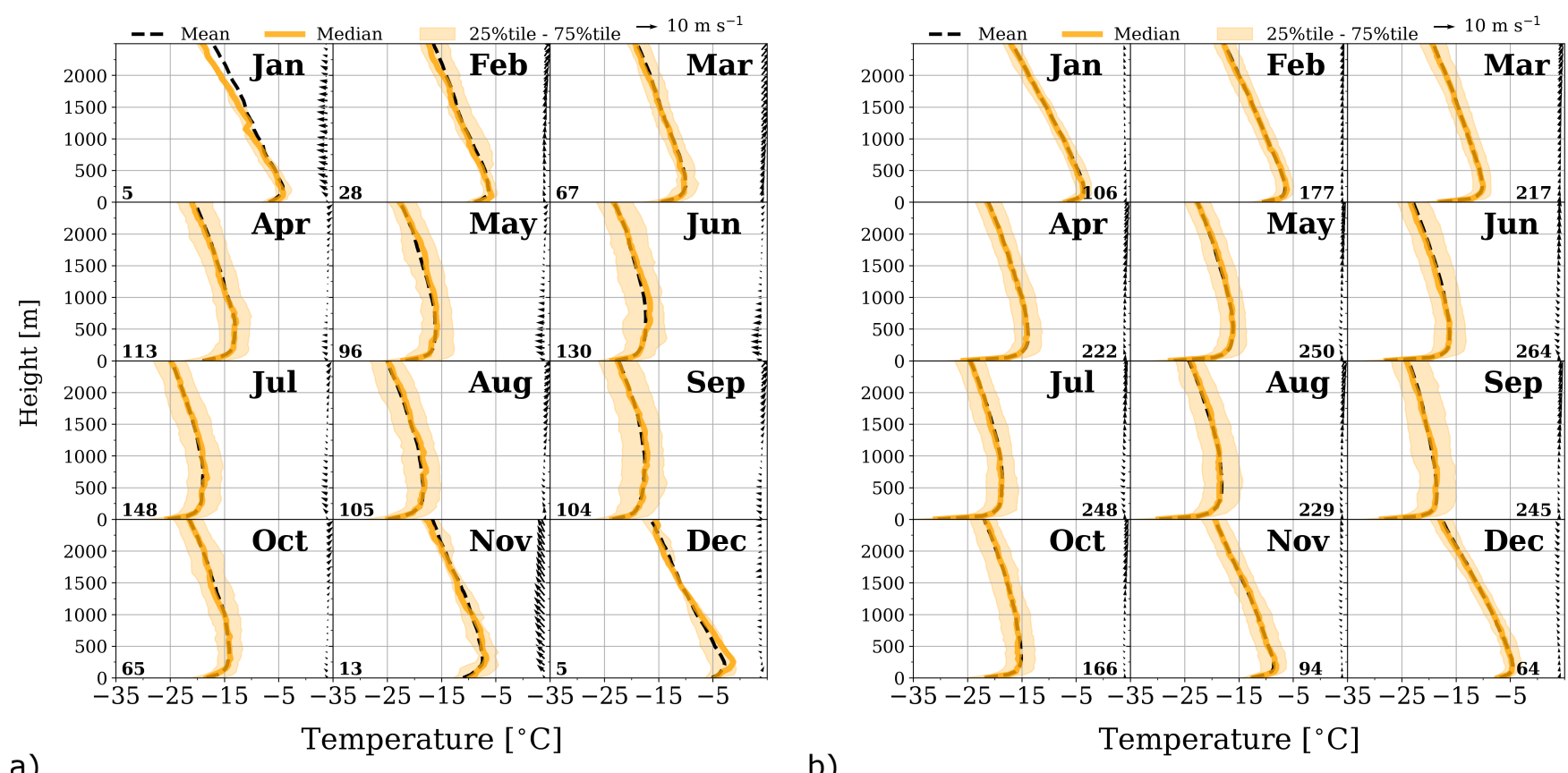

b)

Temperature $\left[{ }^{\circ} \mathrm{C}\right]$

Figure 11. Vertical profiles of the monthly mean (solid) and median (dashed) temperature that detected surface-based temperature inversions. The 25th and 75th percentiles are shaded. in between. The associated mean wind vector (arrows) is in intervals of $100 \mathrm{~m}$ for cyclonic (a) and non-cyclonic (b) conditions. The numbers of cases are given in the lower left corner for each month. 


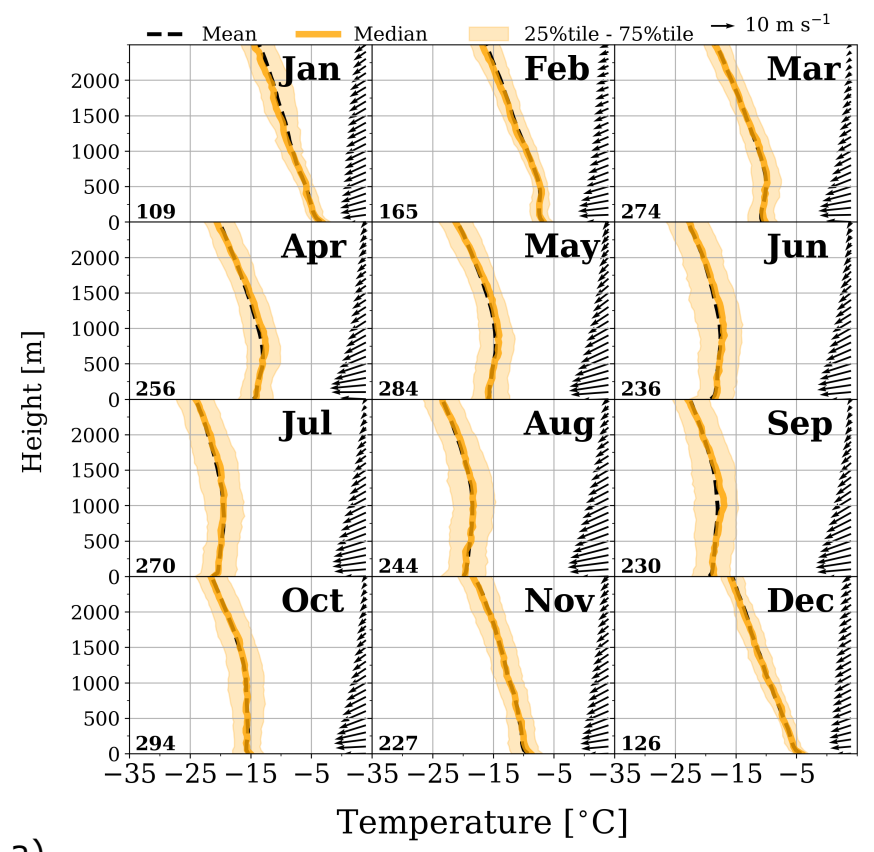

a)

Temperature $\left[{ }^{\circ} \mathrm{C}\right]$

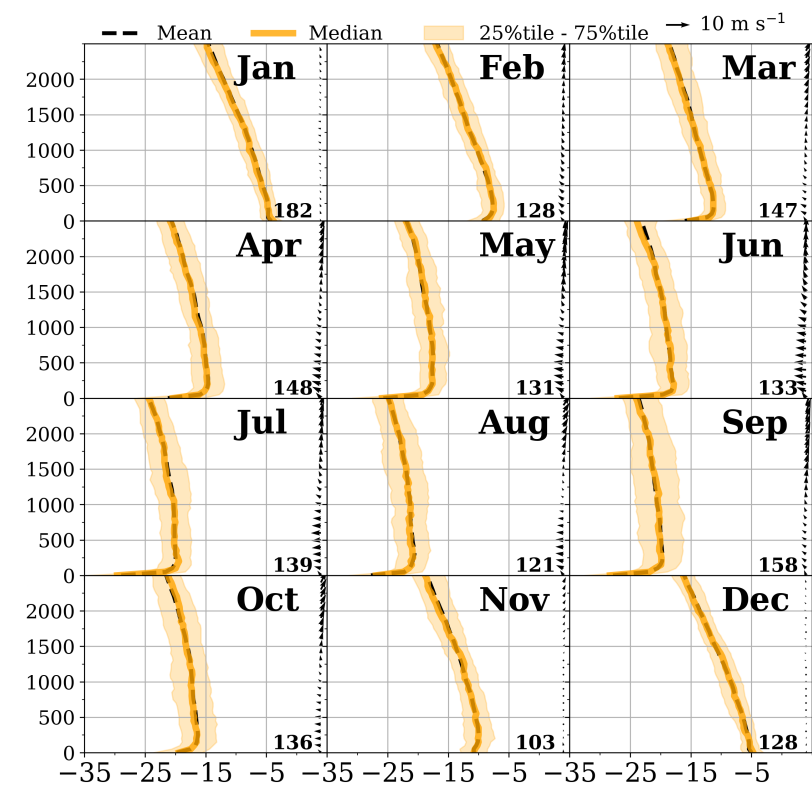

b)

Temperature $\left[{ }^{\circ} \mathrm{C}\right]$

Figure 12. Vertical profiles of the monthly mean (solid) and median (dashed) temperature that detected temperature inversions at the second level. The 25th and 75th percentiles are shaded. in between. The associated mean wind vector (arrows) is in intervals of $100 \mathrm{~m}$ for cyclonic (a) and non-cyclonic (b) conditions. The numbers of cases are given in the lower left corner for each month.

Inversions at the second level, however, are not always detectable in composites because they are either too weak or too variable in height and depth, particularly under non-cyclonic conditions, where also only weak winds are observed. Strikingly different is the picture for elevated inversions under cyclonic conditions (Fig. 12a). Except for the summer months, those inversions are clearly visible in monthly profiles. Wind speeds are considerably higher than in the three other cases. The profiles show strong easterly winds close to the surface, with a Low Level Jet (LLJ) below $500 \mathrm{~m}$ very common throughout the year, except for the summer months November to January. Wind speeds here are higher at the inversion base than at the top, with typical differences of $3 \mathrm{~m} \mathrm{~s}^{-1}$, indicating the proximity of the LLJ to the inversion base. Moreover, this is the only level that fulfils the LLJ definition of Blackadar (1957). Wind direction changes from E to NE, thus counter-clockwise with height, associated with warm air advection. We calculated the percentage of inversions with counter-clockwise rotation of the wind direction from the base to the top of the inversion for the different levels and weather conditions. Corresponding to the results described above, only for the second level and cyclonic conditions a noteworthy difference between cyclonic and non-cyclonic conditions was found for this percentage (66\% and $42 \%$, respectively). Similarly, understanding moisture transport as the simple product of specific humidity and wind speed (e.g. Gorodetskaya et al. 2020; Nygård et al. 2013), a significant upward increase of moisture transport within the inversion was only found for elevated inversions. 
https://doi.org/10.5194/wcd-2021-22

Preprint. Discussion started: 10 May 2021

(c) Author(s) 2021. CC BY 4.0 License.

Weather and

Climate Dynamics

(c) (i)

The corresponding monthly composite humidity profiles (Fig. 13 - surface-based inversions and Fig. 14 inversions at the second level) are basically similar to the temperature profiles, which makes sense since temperature and humidity inversions at the second level are in the majority of cases simultaneous (Fig. 4). Again, only for the second level under cyclonic conditions the wind plays an important role and a LLJ is observed. Generally the humidity profiles show higher variability than the temperature profiles, particularly the surface-based inversions exhibit less smooth profiles than the corresponding temperature profiles due to higher variability in elevation, depth and strength, which also leads to larger differences between median and mean values. Additionally, note the partly low number of cases per month.
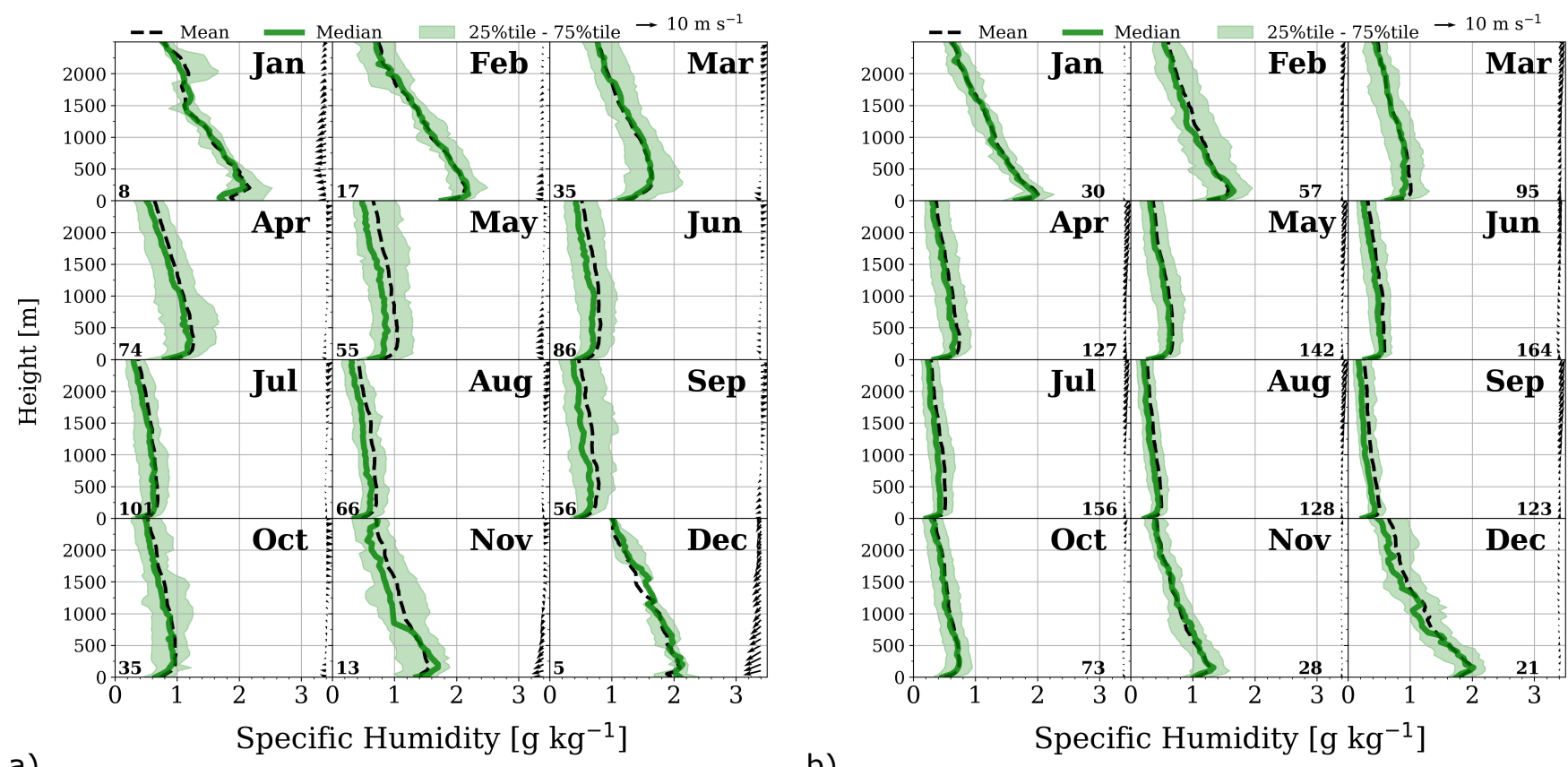

b)

Figure 13. Vertical profiles of the monthly mean (solid) and median (dashed) specific humidity that detected at surface-based humidity inversions. The 25th and 75th percentiles are shaded. in between. The associated mean wind vector (arrows) is in intervals of $100 \mathrm{~m}$ for cyclonic (a) and non-cyclonic (b) conditions. The numbers of cases are given in the lower left corner for each month. 


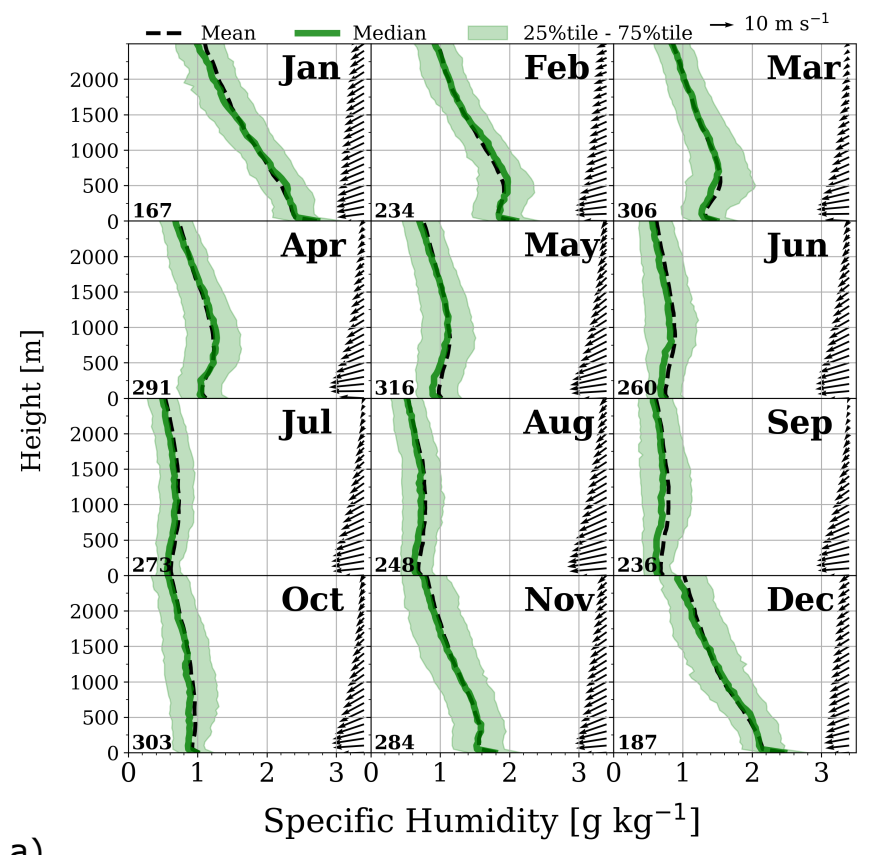

a)

Figure 14. Vertical profiles of the monthly mean (solid) and median (dashed) specific humidity that detected humidity inversions at the second level. The 25th and 75th percentiles are shaded. in between. The associated mean wind vector (arrows) is in intervals of $100 \mathrm{~m}$ for cyclonic (a) and non-cyclonic (b) conditions. The numbers of cases are given in the lower left corner for each month.

\section{Discussion and Conclusion}

For the first time, a 25-yr inversion climatology for Neumayer Station, Antarctica, was presented that takes into account different levels of occurrence and different weather situations. In spite of a relatively simple, dual weather classification clear differences were found for inversion features depending on inversion level and synoptic conditions. Also formation mechanism depended on weather situation and level of occurrence.

Surface-based and elevated inversions show distinctly different features that are related to the formation mechanisms of the inversions, which, in turn, clearly depend on the synoptic situation. This is the case for both temperature and humidity inversions. The relationship between the inversions at the different levels as well as between temperature and humidity inversions are rather complex.

Generally surface-based inversions develop under quiet conditions with low wind speeds, thus little or no turbulent mixing, due to the negative energy balance of the surface. Particularly in winter, when incoming short-wave radiation is low or nonexistent in the polar night, strong inversions are found, corresponding to the winter maxima in general inversion occurrence as well as temperature inversion strength, depth, and vertical gradients. Simultaneously occurring surface-based temperature and 
https://doi.org/10.5194/wcd-2021-22

Preprint. Discussion started: 10 May 2021

(c) Author(s) 2021. CC BY 4.0 License.

(c) (i)

Weather and

Climate Dynamics

Discussions

humidity inversions are partly coupled via the Clausius-Clapeyron Equation (Curry, 1983). However, since the atmosphere is usually not saturated, this is only one general factor. The amount of moisture in the SBL depends on weather history, because sublimation from the cold snow surface is small compared to horizontal advection of moisture. Under non-cyclonic conditions, remainders of moisture advected previously by a passing cyclone can either increase long-wave downward radiation, or, under very cold conditions, fall out as diamond dust. Surface-based humidity inversions are additionally influenced by hoar frost formation, which reduces humidity close to the surface.

Elevated inversions, particularly at the second level and under cyclonic conditions, exhibit high wind speeds, often a LLJ from easterly directions. They are usually associated with the passing of cyclones with the corresponding frontal systems that cause advection of heat and moisture from lower latitudes. Warm air advection above the original cold air at lower levels can thus lead to strong temperature inversions, and the moisture advection causes even stronger and deeper humidity inversions at the second level. This is supported by the counter-clockwise change of wind direction with height (Fig. 12a, 14a).

The relationship between cyclonic activity and elevated inversion occurrence and features can also be seen in the spring and fall maxima of temperature and humidity inversion occurrence under cyclonic conditions at the second level. Here humidity inversion strength exhibits a maximum in spring, which is most likely also related to the spring maximum in baroclinicity (Van Loon, 1967). In contrast, humidity inversion depth shows a winter maximum also at the second level. The reason for the latter is not clear from our investigation, more detailed case studies would be necessary here.

Note that nocturnal inversions in summer could not be detected in the radiosonde launches carried out on a routine base around noon at Neumayer, but are often observed in the morning after clear nights with low wind speed, clearly detectable by the strong mirages that they cause. These inversions are usually short-lived and shallow, the latter being proved by the fact that they are often only visible from the ground and cannot be seen anymore from the station roof $17.5 \mathrm{~m}$ above the surface.

A comparison with earlier studies is only of limited feasibility since, as mentioned before, our study is the first to investigate a long time series of inversions with differentiation between different levels of occurrence and weather situations. Vignon et al. (2019) gave only rather general results for inversions on ice shelves, they focused on near-surface winds and model evaluation. The main result for the two ice shelf stations, Neumayer and Halley, is that they are not influenced by katabatic winds, but they do not show any results that could be compared to our study.

Nygård et al. (2013) also included Neumayer in their study of humidity inversions at 11 Antarctic coastal stations. They had a different attitude, however, e.g. they looked at the number of inversions per ascent rather than studying inversions at a certain level. However, both studies agree, that typically multiple inversions are observed. Nygård et al. (2013) also found that approximately half of the humidity inversions occurred simultaneously with temperature inversions, especially at the surface. Our study yielded higher percentages of simultaneous inversions at the first and second level, whereas, at the third level, humidity inversions associated with temperature inversions were rare. Humidity inversions were found to be most frequent in winter and spring, which corresponds to our results for surface-based inversions under non-cyclonic conditions. For elevated inversion and also for all inversions under cyclonic influence our results are different from those of Nygård et al. (2013). Note that also the chosen thresholds for identifying inversions differed from the ones used in this study. Our choice of thresholds was 
https://doi.org/10.5194/wcd-2021-22

Preprint. Discussion started: 10 May 2021

(c) Author(s) 2021. CC BY 4.0 License.

(c) (i)

Weather and

Climate Dynamics

Discussions

motivated by the interest in the influence of inversions on ice core interpretation. The third level is actually of minor practical importance here.

The use of BSRN (Driemel et al., 2018) vs IGRA (Integrated Global Radiosonde Archive) data (Durre et al., 2006) inhibits the comparison with the Nygård et al. 2013 study and also influences the results to a certain extent. IGRA data provide mostly mandatory pressure levels and thus have lower vertical resolution than the BSRN data. For the same reason, Vignon et al. 2019 also did not use IGRA data, but requested the data from national agencies.

Since Nygård et al. (2013) used a different data set (IGRA, Durre et al. 2006) a data comparison is not feasible. Given differences on the quality control, occasionally certain pressure levels in a profile were not available in one data set but in the other. For the same reason, Vignon et al. (2019) also did not use IGRA data, but requested the data from national agencies.

The division into cyclonic and non-cyclonic conditions is a rather simple one and has its shortcomings, namely that in the transition times when a cyclone was just approaching or moving away, the definition is ambiguous. On the other hand, under non-cyclonic conditions, particularly for humidity inversions the moisture remaining from the cyclone that had just passed plays a role. We chose the 25-yr period, although the change of sensors during this period might have led to inconsistencies, but this disadvantage is small compared to the advantage of using a considerably longer time series than previous studies.

The investigation of moisture transport was done in a rather simple way (described in Subsection 3.5), which is nevertheless meaningful and has been used similarly by other authors (e.g. Dufour et al. 2019; Gorodetskaya et al. 2020). It is beyond the scope of our study to do a detailed calculation of advection terms using atmospheric model output.

The 25-yr inversion climatology presented here is supposed to serve as a first step towards a better understanding of Antarctic inversion features, which will help to improve the current paleoclimatic interpretation of ice cores (e.g. Jouzel and Merlivat 1984). We used monthly mean (median) values to do statistical calculations of inversion occurrence and features. For a more detailed analysis, higher temporal resolution combined with surface energy balance studies as well as a more complex weather situation classification would be recommended. Additionally, the use of model data to explicitly calculate moisture and heat advection would help to get a deeper insight into formation mechanisms, particularly for elevated inversions.

Data availability. All data sets of upper-air soundings and synoptic weather observations covering the entire study period at Neumayer Station are publicly available either at website PANGAEA or at Baseline Surface Radiation Network website.

Author contributions. TS and ES structured the study, TS did the data analysis, TS and ES interpreted the results and wrote the manuscript.

Competing interests. The authors declare that they have no conflict of interest. 
https://doi.org/10.5194/wcd-2021-22

Preprint. Discussion started: 10 May 2021

(c) Author(s) 2021. CC BY 4.0 License.

Weather and

Climate Dynamics

(c) (1)

Discussions

L

425 Acknowledgements. We are grateful to the scientific wintering staff at Neumayer Station for carrying out radiosonde launches and SYNOP observations under the harsh Antarctic conditions. We would also like to thank Holger Schmithüsen and Amelie Driemel from AlfredWegener Institute, Bremerhaven, for continuous technical support with data.

Sincere thanks to Manuela Lehner for critical reading of the manuscript.

Tiago Silva was financially supported by the Research Center "Climate - Cryosphere and Atmosphere" of the University of Innsbruck, 430 Austria.

This study is part of a project funded by the Austrian Science Fund (FWF) under grant P28695. 
https://doi.org/10.5194/wcd-2021-22

Preprint. Discussion started: 10 May 2021

(C) Author(s) 2021. CC BY 4.0 License.

\section{References}

Andreas, E. L., Claffy, K. J., and Makshtas, A. P.: Low-level atmospheric jets and inversions over the western Weddell Sea, Boundary-layer meteorology, 97, 459-486, https://doi.org/10.1023/A:1002793831076, 2000.

Bintanja, R., Graversen, R., and Hazeleger, W.: Arctic winter warming amplified by the thermal inversion and consequent low infrared cooling to space, Nature Geoscience, 4, 758, https://doi.org/10.1038/ngeo1285, 2011.

Blackadar, A. K.: Boundary layer wind maxima and their significance for the growth of nocturnal inversions, Bulletin of the American Meteorological Society, 38, 283-290, https://doi.org/10.1175/1520-0477-38.5.283, 1957.

Brunke, M. A., Stegall, S. T., and Zeng, X.: A climatology of tropospheric humidity inversions in five reanalyses, Atmospheric Research, 153, 165-187, https://doi.org/10.1016/j.atmosres.2014.08.005, 2015.

Curry, J.: On the formation of continental polar air, Journal of the Atmospheric Sciences, 40, 2278-2292, https://doi.org/10.1175/15200469(1983)040<2278:OTFOCP>2.0.CO;2, 1983.

Devasthale, A., Sedlar, J., and Tjernström, M.: Characteristics of water-vapour inversions observed over the Arctic by Atmospheric Infrared Sounder (AIRS) and radiosondes, Atmospheric Chemistry and Physics, 11, 9813-9823, https://doi.org/10.5194/acp-11-9813-2011, 2011.

Driemel, A., Augustine, J., Behrens, K., Colle, S., Cox, C., Cuevas-Agulló, E., Denn, F. M., Duprat, T., Fukuda, M., Grobe, H., et al.: Baseline Surface Radiation Network (BSRN): structure and data description (1992-2017), Earth System Science Data, 10, 1491-1501, https://doi.org/10.5194/essd-10-1491-2018, 2018.

Dufour, A., Charrondière, C., and Zolina, O.: Moisture transport in observations and reanalyses as a proxy for snow accumulation in East Antarctica, The Cryosphere, 13, 413-425, https://doi.org/10.5194/tc-13-413-2019, 2019.

Durre, I., Vose, R. S., and Wuertz, D. B.: Overview of the integrated global radiosonde archive, Journal of Climate, 19, 53-68, https://doi.org/10.1175/JCLI3594.1, 2006.

Gettelman, A., Walden, V., Miloshevich, L., Roth, W., and Halter, B.: Relative humidity over Antarctica from radiosondes, satellites, and a general circulation model, Journal of Geophysical Research: Atmospheres, 111, https://doi.org/10.1029/2005JD006636, 2006.

Gorodetskaya, I. V., Silva, T., Schmithuesen, H., and Hirasawa, N.: Atmospheric River Signatures in Radiosonde Profiles and Reanalyses at the Dronning Maud Land Coast, East Antarctica, ADVANCES IN ATMOSPHERIC SCIENCES, 37, 455-476, https://doi.org/10.1007/s00376-020-9221-8, 2020.

Hudson, S. R., Town, M. S., Walden, V. P., and Warren, S. G.: Temperature, humidity, and pressure response of radiosondes at low temperatures, Journal of Atmospheric and Oceanic Technology, 21, 825-836, https://doi.org/10.1175/15200426(2004)021<0825:THAPRO>2.0.CO;2, 2004.

Jouzel, J. and Merlivat, L.: Deuterium and oxygen 18 in precipitation: Modeling of the isotopic effects during snow formation, Journal of Geophysical Research: Atmospheres, 89, 11 749-11 757, https://doi.org/10.1029/JD089iD07p11749, 1984.

Kahl, J. D.: Characteristics of the low-level temperature inversion along the Alaskan Arctic coast, International Journal of Climatology, 10, 537-548, https://doi.org/10.1002/joc.3370100509, 1990.

Kilpeläinen, T., Vihma, T., Manninen, M., Sjöblom, A., Jakobson, E., Palo, T., and Maturilli, M.: Modelling the vertical structure of the atmospheric boundary layer over Arctic fjords in Svalbard, Quarterly Journal of the Royal Meteorological Society, 138, 1867-1883, https://doi.org/10.1002/qj.1914, 2012.

King, J. C. and Turner, J.: Antarctic meteorology and climatology, Cambridge University Press, 2007. 
https://doi.org/10.5194/wcd-2021-22

Preprint. Discussion started: 10 May 2021

(C) Author(s) 2021. CC BY 4.0 License.

(c) (i)

Weather and

Climate Dynamics

Discussions

König-Langlo, G. and Loose, B.: The meteorological observatory at neumayer stations (gvn and nm-ii) Antarctica, Polarforschung2006, 76, 25-38, 2007.

Liu, Y., Key, J. R., Schweiger, A., and Francis, J.: Characteristics of satellite-derived clear-sky atmospheric temperature inversion strength in the Arctic, 1980-96, Journal of climate, 19, 4902-4913, 10.1175/JCLI3915.1, 2006.

Maturilli, M. and Kayser, M.: Arctic warming, moisture increase and circulation changes observed in the Ny-Ålesund homogenized radiosonde record, Theoretical and Applied Climatology, 130, 1-17, https://doi.org/10.1007/s00704-016-1864-0, 2017.

Miloshevich, L. M., Vömel, H., Paukkunen, A., Heymsfield, A. J., and Oltmans, S. J.: Characterization and correction of relative humidity measurements from Vaisala RS80-A radiosondes at cold temperatures, Journal of Atmospheric and Oceanic Technology, 18, 135-156, https://doi.org/10.1175/1520-0426(2001)018<0135:CACORH>2.0.CO;2, 2001.

Miloshevich, L. M., Paukkunen, A., Vömel, H., and Oltmans, S. J.: Development and validation of a time-lag correction for Vaisala radiosonde humidity measurements, Journal of Atmospheric and Oceanic Technology, 21, 1305-1327, https://doi.org/10.1175/15200426(2004)021<1305:DAVOAT>2.0.CO;2, 2004.

Miloshevich, L. M., Vömel, H., Whiteman, D. N., Lesht, B. M., Schmidlin, F., and Russo, F.: Absolute accuracy of water vapor measurements from six operational radiosonde types launched during AWEX-G and implications for AIRS validation, Journal of Geophysical Research: Atmospheres, 111, https://doi.org/10.1029/2005JD006083, 2006.

Nash, J.: Measurement of upper-air pressure, temperature and humidity, World Meteorological Organization IOM Rep, p. 87, 2015.

Nash, J., Oakley, T., Vömel, H., and Wei, L.: WMO intercomparison of high quality radiosonde systems, Yangjiang, China, 12 July-3 August 2010, World Meteorological Organization, Instruments and Observing methods, report No, 107, 2011.

Nygård, T., Valkonen, T., and Vihma, T.: Antarctic low-tropospheric humidity inversions: 10-yr climatology, Journal of Climate, 26, 52055219, https://doi.org/10.1175/JCLI-D-12-00446.1, 2013.

Ohmura, A.: Physical basis for the temperature-based melt-index method, Journal of applied Meteorology, 40, 753-761, https://doi.org/10.1175/1520-0450(2001)040<0753:PBFTTB>2.0.CO;2, 2001.

on WMO codes, M.: Manual on Codes: International Codes Volume I. 1 Annex II to the WMO Technical Regulations Part A-Alphanumeric Codes, 2016.

Pavelsky, T. M., Boé, J., Hall, A., and Fetzer, E. J.: Atmospheric inversion strength over polar oceans in winter regulated by sea ice, Climate dynamics, 36, 945-955, https://doi.org/10.1007/s00382-010-0756-8, 2011.

Phillpot, H. and Zillman, J.: The surface temperature inversion over the Antarctic continent, Journal of Geophysical Research, 75, 4161-4169, https://doi.org/10.1029/JC075i021p04161, 1970.

Rowe, P. M., Miloshevich, L. M., Turner, D. D., and Walden, V. P.: Dry bias in Vaisala RS90 radiosonde humidity profiles over Antarctica, Journal of Atmospheric and Oceanic Technology, 25, 1529-1541, https://doi.org/10.1175/2008JTECHA1009.1, 2008.

Tomasi, C., Petkov, B., Benedetti, E., Valenziano, L., and Vitale, V.: Analysis of a 4 year radiosonde data set at Dome C for characterizing temperature and moisture conditions of the Antarctic atmosphere, Journal of Geophysical Research: Atmospheres, 116, https://doi.org/10.1029/2011JD015803, 2011.

Van Loon, H.: The half-yearly oscillations in middle and high southern latitudes and the coreless winter, Journal of the Atmospheric Sciences, 24, 472-486, https://doi.org/tps://doi.org/10.1175/1520-0469(1967)024<0472:THYOIM>2.0.CO;2, 1967.

Vignon, É., Traullé, O., and Berne, A.: On the fine vertical structure of the low troposphere over the coastal margins of East Antarctica, Atmospheric Chemistry and Physics, 19, 4659-4683, https://doi.org/10.5194/acp-19-4659-2019, 2019. 
https://doi.org/10.5194/wcd-2021-22

Preprint. Discussion started: 10 May 2021

(c) Author(s) 2021. CC BY 4.0 License.

Weather and

Climate Dynamics

(c) (i)

505 Vihma, T., Kilpeläinen, T., Manninen, M., Sjöblom, A., Jakobson, E., Palo, T., Jaagus, J., and Maturilli, M.: Characteristics of temperature and humidity inversions and low-level jets over Svalbard fjords in spring, Advances in Meteorology, 2011, https://doi.org/10.1155/2011/486807, 2011.

Wang, J., Cole, H. L., Carlson, D. J., Miller, E. R., Beierle, K., Paukkunen, A., and Laine, T. K.: Corrections of humidity measurement errors from the Vaisala RS80 radiosonde-Application to TOGA COARE data, Journal of Atmospheric and Oceanic Technology, 19, 981-1002,

510 https://doi.org/10.1175/1520-0426(2002)019<0981:COHMEF>2.0.CO;2, 2002.

Wesche, C., Weller, R., König-Langlo, G., Fromm, T., Eckstaller, A., Nixdorf, U., and Kohlberg, E.: Neumayer III and Kohnen Station in Antarctica operated by the Alfred Wegener Institute, Journal of large-scale research facilities JLSRF, 2, 85, https://doi.org/http://dx.doi.org/10.17815/jlsrf-2-152, 2016.

Zhang, Y., Seidel, D. J., Golaz, J.-C., Deser, C., and Tomas, R. A.: Climatological characteristics of Arctic and Antarctic surface-based inversions, Journal of Climate, 24, 5167-5186, https://doi.org/10.1175/2011JCLI4004.1, 2011. 